\title{
REVIEWS
}

\section{New Macromolecular Architectures for Permselective Membranes - Gas Permselective Membranes from Dendrimers and Enantioselectively Permeable Membranes from One-handed Helical Polymers-}

\author{
Toshiki AOKI ${ }^{1,2,3, \dagger}$ and Takashi KANEKO ${ }^{1,2}$ \\ ${ }^{1}$ Department of Chemistry and Chemical Engineering, Faculty of Engineering, Niigata University, \\ Ikarashi 2-8050, Niigata 950-2181, Japan \\ ${ }^{2}$ Center for Transdisciplinary Research, Niigata University, Ikarashi 2-8050, Niigata 950-2181, Japan \\ ${ }^{3}$ Graduate School of Science and Technology, Niigata University, Ikarashi 2-8050, Niigata 950-2181, Japan
}

(Received June 30, 2005; Accepted June 30, 2005; Published October 15, 2005)

\begin{abstract}
Chemistry of macromolecular architecture is one of the fastest growing branches of polymer chemistry. The present review describes macromolecular architectures for permselective membranes relating their structures and permselectivity, and is focused on dendrimers for gas permselective membranes and one-handed helical polymer membranes for enantioselectively permeable membranes (optical resolution). The first part of this review described the three kinds of permselective membranes prepared from pure polydendrons or dendronized polymers having self-membrane-forming ability by us, and from another polymer and dendrimers or hyperbranched polymers as a crosslinker, and from another supporting membrane and dendrimers as a modifier. The membranes from polydendrons showed better oxygen permselectivities than those of conventional polymer membranes. In the second part, three kinds of enantioselectively permeable membranes reported by many researchers, i.e., chiral carriers-containing composite membranes, membranes based on chiral HPLC stationary phase polymers, and chiral molecular imprinting membranes, are reviewed briefly. In particular, the detail of our macromolecular designs of one-handed helical poly(substituted acetylene)s as materials for enantioselectively permeable membranes is discussed as the fourth category. When the content of the chiral groups was higher, the permselectivity was enhanced. The one-handed helical backbones were found to be effective for enantioselective permeation. It was also shown that the disadvantage of this method, i.e., low permeation rate was improved by using thinner membranes. In addition, enantioselectively permeable membranes are classified from the view point of their permeation mechanisms. [DOI 10.1295/polymj.37.717]

KEY WORDS Permselective Membrane / Gas Permselectivity / Enantioselective Permeation / Poly(substituted acetylenes) / Silyl Group / Dendrimer / Polydendron / Chiral Groups / One-handed Helical Main-chain /
\end{abstract}

\section{INTRODUCTION}

It has been well known that natural macromolecules offer an excellent harmony in the structure, the organization, and the properties. Recently, much attention has been focused on making the harmony artificially in synthetic polymer materials whose structures are precisely controlled by using highly developed methods for polymer synthesis and characterization. In particular, new macromolecular architectures which are not linear and not a random coil but are unique in the primary and secondary structures have attracted much attention because of their expected novel properties. In particular, dendrimers and one-handed helical polymers have been reported by researchers in many kinds of fields among new macromolecular architectures. Dendrimers have a well-defined branched structure, and therefore, they have controlled molecular-scale spaces between branches. The well-defined spaces are very attractive to control permselectivities for small molecules like gases. Separation of gases like $\mathrm{O}_{2}$ and $\mathrm{CO}_{2}$ through permselective membranes is a very promising method to solve the energy or environmental problems. On the other hand, optical resolution through permselective membranes is expected to solve easily the harmful effects of a medicine. One-handed helical polymers show chirality. The chiral structure can be found not in small organic molecules but only in macromolecules and is much larger than that in small organic molecules. Since one-handed helical polymers can have high content of chiral structures over a membrane, they are a promising candidate for a material for highly enantioselectively permeable membranes.

In this review, we describe dendrimers and one-

${ }^{\dagger}$ To whom correspondence should be addressed (E-mail: toshaoki@eng.niigata-u.ac.jp). 
handed helical polymers as new macromolecular architectures, and gas permselective permeation and enantioselective permeation as novel properties of them, respectively.

\section{DENDRIMERS FOR GAS PERMSELECTIVE MEMBRANES}

\subsection{Dendrimers as Permselective Membrane Materials}

Dendrimers are characterized by a regularly and fractally branched treelike architecture, and this feature would provide three-dimensional shape-persistency depending on their precisely defined chemical structures. ${ }^{1}$ Since 1990, the field has explosively grown including theory, synthesis, structural characterization, properties and functional application. The chemical structure and/or morphology of polymers play an important role for the permselectivity of nonporous(dense) membranes. It is believed that the more homogeneous morphology in horizontal direction membranes have, the better performance they show. Therefore, the dendrimers would be available to the membranes for molecular recognition and/or permselective permeation based on the following structural features; 1) dendrimers have the fractally similar interior structure over huge region due to the high molecular weight, and 2) the center and periphery of a dendrimer molecule are often able to be modified by favorable substituent groups. These features would lead to creating a great number of precise molecular recognition sites in polymers, and a nano-scale asymmetric structure like asymmetric membranes. However, there were almost no reports about dendrimers for the permselective membranes until very recent period. Probably because most of the synthesized dendrimers were spherical or globular, and usually showed a low viscosity, they were unfavorable for fabricating selfsupporting membranes.

We had already paid attention to these points at an early stage, and had synthesized monodendron monomers consisting of $m$-linked phenyleneethynylene repeating units with trimethylsilyl peripheral groups, and obtained the corresponding polydendrons by the homopolymerization of the monomers using a Rh catalyst. $^{2}$ The polydendrons were fabricated to self-supporting membranes, and the membrane showed good performance for oxygen permselectivity.

\subsection{Classification of Dendrimers for Permselective Membranes}

Besides our investigation on polydendrons having self-membrane-forming ability, there are the other two types of permselective membranes using dendrimers or hyperbranched polymers reported recently. These membranes were fabricated by the following two methods, since most of the dendrimers had no self-membrane-forming ability. One is the membranes from polymers crosslinked by the dendrimers which have reactive peripheral groups, and the other is the composite membranes from dendrimers and a supporting membrane. We reviewed these three permselective membranes which contained dendrimers or dendritic structures in the following sections (2.3-2.5).

\subsection{Polydendrons and Dendronized Polymers for Permselective Membranes}

The shapes of dendrimers should be significantly affected by the core group structures. If we use a linear molecule for the core group instead of a small spot molecule, a cylindrical or rod-like macromolecule with uniform diameter will be yielded which preserves the advantages of dendrimer such as a welldefined dendritic structure with many functional groups localized on the periphery of dendrimer. The side chain dendritic or dendronized polymers can be synthesized from the corresponding core polymers by use of the same methodology as the usual dendrimer syntheses, i.e., the divergent and convergent approach. ${ }^{3}$ For the extension of the convergent approach, the cylindrical or rod-like dendrimers can be synthesized by polymerization of a polymerizable group attached to the focal point of the monodendron. In view of the shape-persistency, the polymerization of monodendron is preferred to the polymer reaction methods since it is difficult for polymer reactions such as these methods to complete attachment of the dendron-building blocks or the monodendron onto a reactive polymer chain. It was also difficult for homopolymerization of monodendron monomers over the second generation to achieve a high degree of polymerization $(D P)$ due to steric hindrance of the bulky side chain dendron. ${ }^{3}$

We paid attention to poly(phenylacetylene) structures for the central core molecule because it is known that poly(phenylacetylene)s were yielded by some rhodium complex catalysts with high degrees of polymerization and stereoregularities, i.e., cis-transoidal and helical structures. ${ }^{2}$ The monodendrons with the terminal acetylene group at the focal point were synthesized as shown in Scheme 1.,4-12 The monodendron monomers gave the corresponding polydendrons by the polymerization with $[\mathrm{Rh}(\mathrm{nbd}) \mathrm{Cl}]_{2}$ catalyst (Scheme 2). The detailed polymerization conditions and the characterization of polymers are tabulated in Table I. The polydendrons showed high solubility in common solvents, and had a high degree of polymerization $\left(D P>10^{3}\right)$ under the polymerization conditions. However, the yield and degree of polymerization decreased as the increment of generation in the same polymerization conditions. The structural 


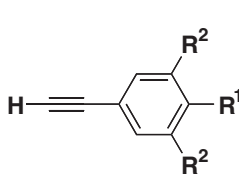

TMSOH $: \mathbf{R}^{\mathbf{1}}=-\mathbf{S i}\left(\mathrm{CH}_{3}\right)_{3}, \mathbf{R}^{2}=-\mathbf{H}$

PMDSOH : $\mathbf{R}^{1}=-\mathrm{Si}\left(\mathrm{CH}_{3}\right)_{2} \mathrm{OSi}\left(\mathrm{CH}_{3}\right)_{3}, \mathbf{R}^{2}=-\mathbf{H}$

NMTSOH : $\mathbf{R}^{1}=-\left[\mathrm{Si}^{1}\left(\mathrm{CH}_{3}\right)_{2} \mathrm{O}\right]_{3} \mathrm{Si}\left(\mathrm{CH}_{3}\right)_{3}, \mathbf{R}^{2}=-\mathbf{H}$

$\mathrm{Hex} 0 \mathrm{H}: \mathbf{R}^{1}=-\left(\mathrm{CH}_{2}\right)_{5} \mathbf{C H}_{3}, \mathbf{R}^{2}=-\mathbf{H}$

DBOH $: \mathbf{R}^{1}=-\mathbf{H}, \mathbf{R}^{2}=-\mathbf{C}\left(\mathbf{C H}_{3}\right)_{3}$

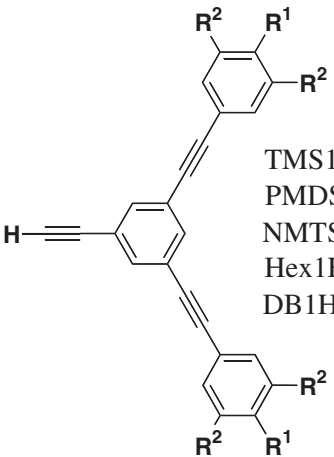

TMS1H $: \mathbf{R}^{1}=-\mathbf{S i}\left(\mathrm{CH}_{3}\right)_{3}, \mathbf{R}^{2}=-\mathbf{H}$

PMDS1H : $\mathbf{R}^{1}=-\mathrm{Si}\left(\mathrm{CH}_{3}\right)_{2} \mathrm{OSi}\left(\mathrm{CH}_{3}\right)_{3}, \mathbf{R}^{2}=-\mathrm{H}$

NMTS1H : $\mathbf{R}^{1}=-\left[\mathrm{Si}^{2}\left(\mathrm{CH}_{3}\right)_{2} \mathrm{O}\right]_{3} \mathrm{Si}\left(\mathrm{CH}_{3}\right)_{3}, \mathbf{R}^{2}=-\mathbf{H}$

$\mathrm{Hex} 1 \mathrm{H} \quad: \mathbf{R}^{1}=-\left(\mathbf{C H}_{2}\right)_{5} \mathbf{C H}_{3}, \mathbf{R}^{2}=-\mathbf{H}$

DB1H $: \mathbf{R}^{1}=-\mathbf{H}, \mathbf{R}^{2}=-\mathbf{C}\left(\mathrm{CH}_{3}\right)_{3}$

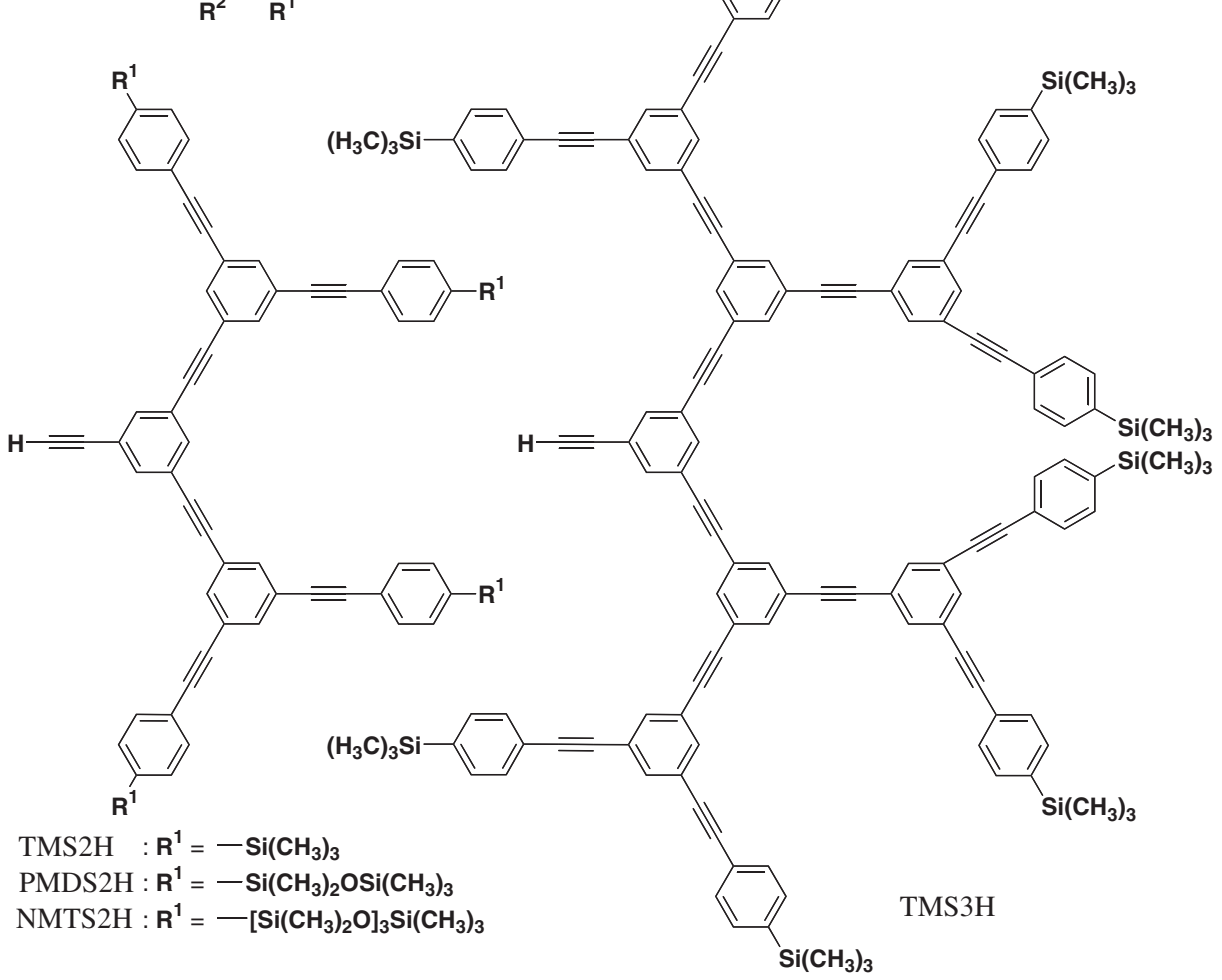

Scheme 1-1.

features of the polydendrons were estimated by the measurement of ${ }^{1} \mathrm{H}$ NMR, ${ }^{13} \mathrm{C}$ NMR, UV-vis spectra, wide angle X-ray scattering (WAXS), atomic force microscopy (AFM), gel permeation chromatography(GPC) and low angle laser light scattering (GPCLALLS), and other instruments. ${ }^{2,6}$ The results indicated their rod- or worm-like structures, which had cistransoidal main-chain and the well-defined monodendron plane, and had a highly twisted dihedral angle between the main-chain and the attached monodendron plane, and, counteractingly, slightly or moderately twisted single bonds of the main-chain, and whose dendron planes were arranged along the main-chain. The polydendrons showed good self-membrane-forming property when their degree of polymerization was high, and gave a self-supporting membrane with or- ange color due to $\pi$-conjugated main-chain chromophore by the solvent casting method.

The relationship between the oxygen permeability coefficient $\left(P_{\mathrm{O}_{2}}\right)$ and the oxygen separation factor $\left(\alpha=P_{\mathrm{O}_{2}} / P_{\mathrm{N}_{2}}\right)$ for the polydendron membranes are summarized together with those for membranes from the zero generation polymers (poly $(\mathrm{TMSOH})$, poly( $\mathrm{PMDSOH})$ and poly(NMTSOH)) in Figure $1 .^{2,7,10,13,14,17}$ The zero generation poly(phenylacetylene) derivatives showed a trade off line between $P_{\mathrm{O}_{2}}$ and $\alpha$. However, the $P_{\mathrm{O}_{2}}$ values of the polydendrons with trimethylsilyl group, poly(TMS1H), poly(TMS1PEH) and poly(TMSTPA1), showed good performance in comparison with the corresponding zero generation of poly(phenylacetylene) derivatives. On the other hand, those of the polydendrons with oligo- 


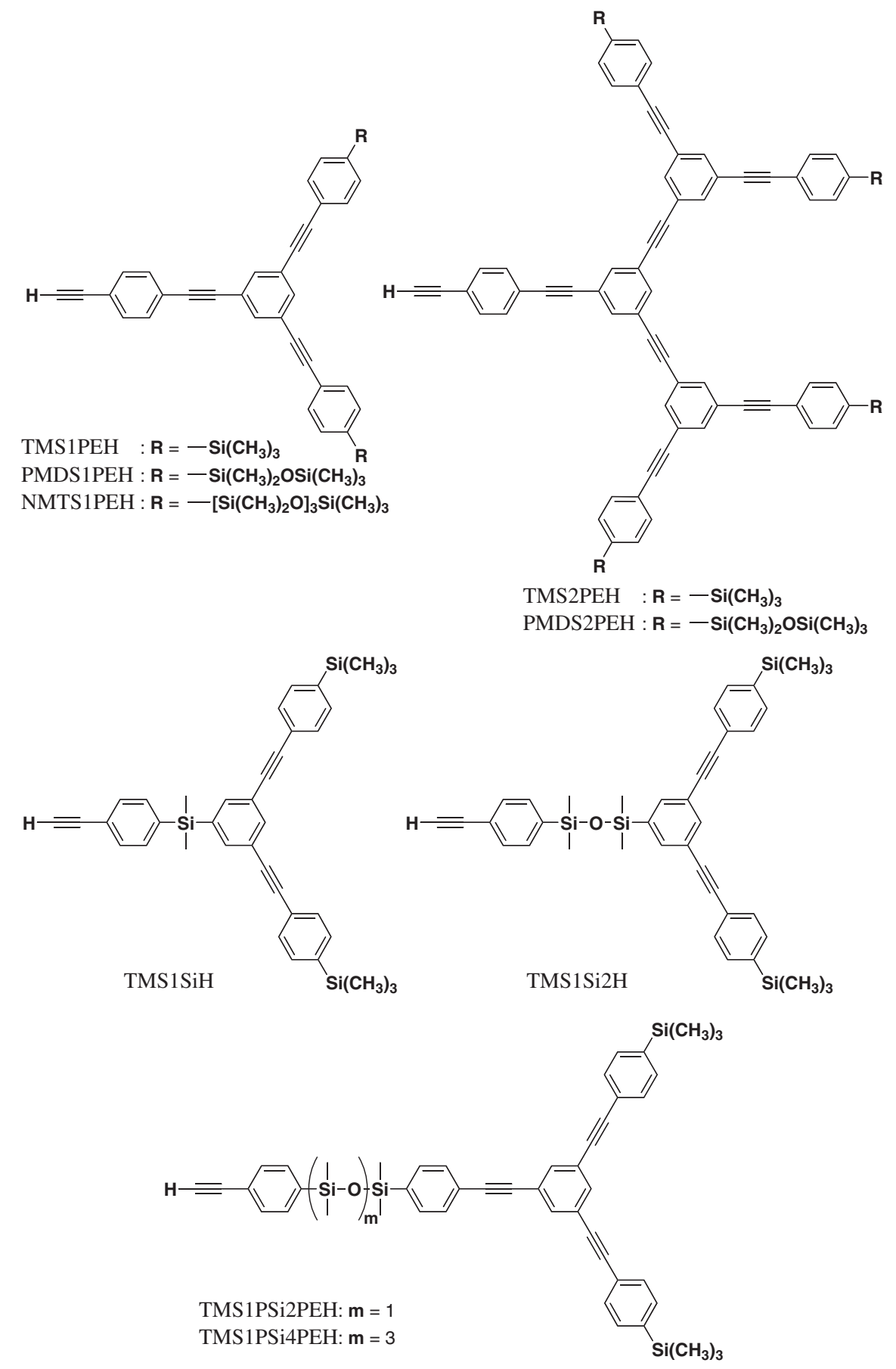

Scheme 1-2.

dimethylsiloxane peripheral groups, poly(PMDS1H), poly(PMDS1PEH) and poly(NMTS1PEH), were similar to the corresponding zero generation poly(phenylacetylene) derivatives. The solution selectivity $\left(S_{\mathrm{O}_{2}} /\right.$ $S_{\mathrm{N}_{2}}$ ) depended on the peripheral groups except for poly(TMSTPA1), and the $S_{\mathrm{O}_{2}} / S_{\mathrm{N}_{2}}$ value of polydendrons was similar to that of the corresponding zero generation poly(phenylacetylene)s. ${ }^{7}$ Therefore, the high performance of the oxygen permselectivity in poly(TMS1H) and poly(TMS1PEH) was explained from the diffusion selectivity $\left(D_{\mathrm{O}_{2}} / D_{\mathrm{N}_{2}}\right)$ which was improved by the space-persistency due to the stiff and crowded dendritic structure. On the other hand, the high performance of the oxygen permselectivity in poly(TMSTPA1) depended on $S_{\mathrm{O}_{2}} / S_{\mathrm{N}_{2}}{ }^{10}$

\subsection{Permselective Membranes from Polymers Cross-} linked by Dendrimers

2.4.1. Dendrimers as a Closslinker. It is well known that linear polyimide membranes show good gas separation performance. Crosslinking modifications of their membranes were carried out in order to overcome the problem that most of polyimide membranes suffered severe aging and performance decay 

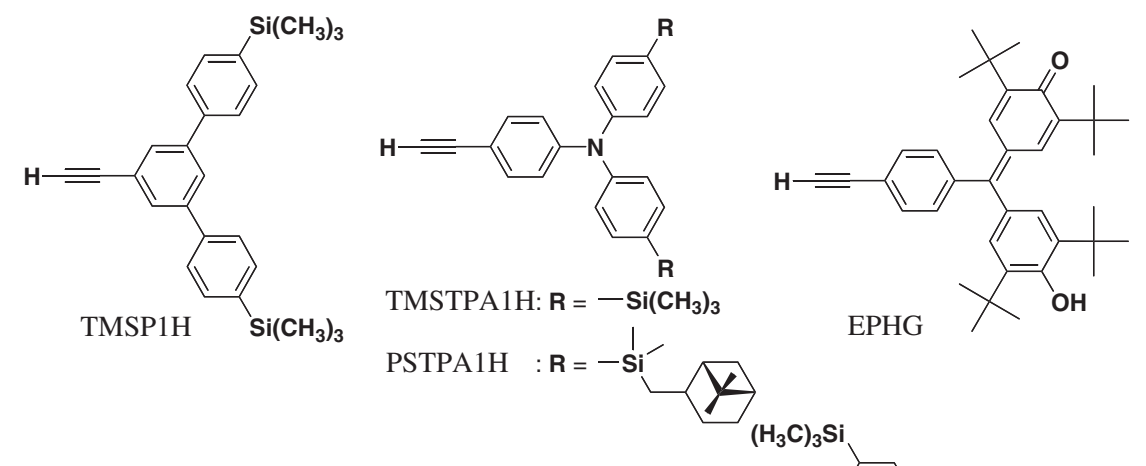

EPHG

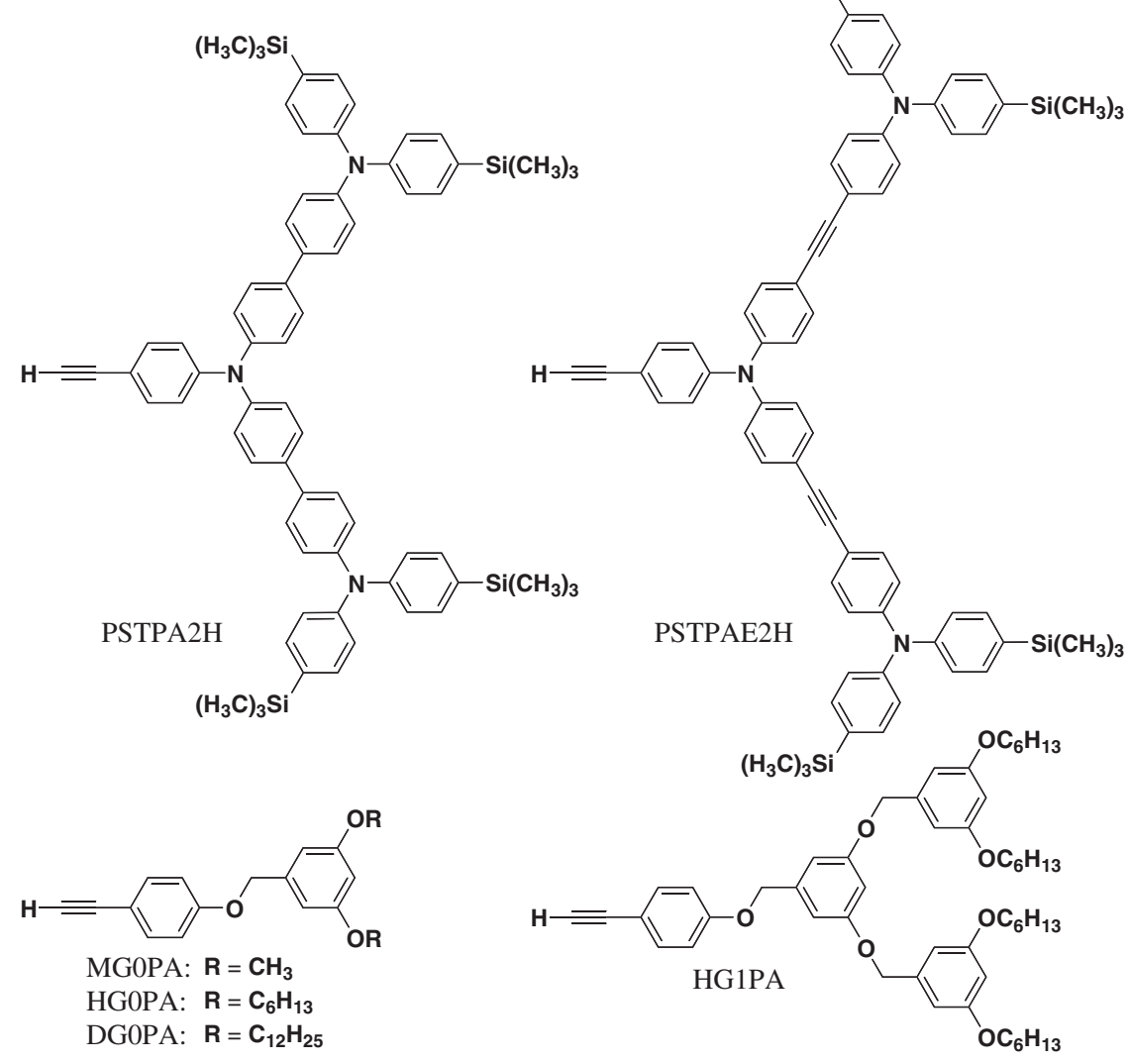

Scheme 1-3.

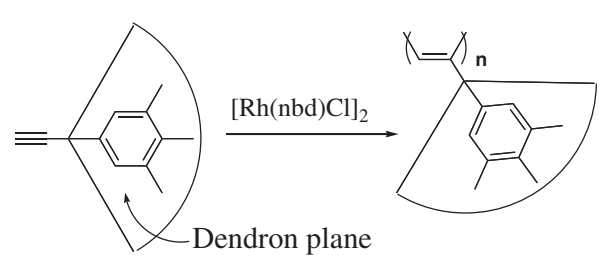

Scheme 2.

due to densification and/or plasticization. ${ }^{19}$ Recently, 6FDA-durene polyimide membrane was crosslinked with polyamidoamine (PAMAM) or polypropyleneimine (DAB-AM) dendrimers (Scheme 3). ${ }^{20-22}$ The DAB-AM dendrimer-crosslinked membranes were prepared by immersing the polymer membranes into a $5 \%(\mathrm{w} / \mathrm{w})$ dendrimer $(\mathrm{G} 1-\mathrm{G} 3)$ methanol solution. ${ }^{20}$ The crosslinking modifications were confirmed by the measurements of gel content and FT-IR, and the degree of crosslinking was the following order: G1 > G2 > G3 at the same crosslinking time. The pure gas ( $\mathrm{He}, \mathrm{H}_{2}, \mathrm{O}_{2}, \mathrm{~N}_{2}, \mathrm{CH}_{4}$ and $\mathrm{CO}_{2}$ ) permeability was examined, and the permeability decreased with increasing the crosslinking time but the selectivity increased by about 400,300 and $265 \%$ for the gas pairs of $\mathrm{He} / \mathrm{N}_{2}, \mathrm{H}_{2} / \mathrm{N}_{2}$ and $\mathrm{H}_{2} / \mathrm{CO}_{2}$, respectively, after 60 min of crosslinking with $\mathrm{G} 1$ dendrimers. In particular, this increment in the $\mathrm{H}_{2} / \mathrm{CO}_{2}$ selectivity was more impressive than the other polyimide modifications. However, the selectivity increments for 60min G1, G2 and G3 crosslinked samples were about 400, 200 and $160 \%$, respectively, which coincided with the order of the degrees of crosslinking. The PAMAM dendrimer (G0-G2) crosslinked membranes were also prepared by the same procedure. ${ }^{21,22}$ G0 PAMAM dendrimer penetrated the polymer matrix deeply and reacted with polyimide chains, and the 
Table I. Polymerization of phenylacetylene monodendrons using $[\mathrm{Rh}(\mathrm{nbd}) \mathrm{Cl}]_{2}{ }^{\mathrm{a}}$ and characterization of polydendrons

\begin{tabular}{|c|c|c|c|c|c|c|c|c|c|c|c|c|c|c|}
\hline \multirow[b]{2}{*}{ Monomer } & \multirow{2}{*}{$\begin{array}{c}\text { Generation } \\
\text { number }\end{array}$} & \multirow{2}{*}{$\begin{array}{c}\text { Spacing } \\
\text { unit }^{b}\end{array}$} & \multirow{2}{*}{$\begin{array}{l}\text { Yield } \\
(\%)\end{array}$} & \multirow{2}{*}{$\begin{array}{c}M_{\mathrm{w}}{ }^{\mathrm{c}} \\
\left(\times 10^{6}\right)\end{array}$} & \multirow[b]{2}{*}{$M_{\mathrm{w}} / M_{\mathrm{n}}{ }^{\mathrm{c}}$} & \multirow{2}{*}{$\begin{array}{c}D P^{\mathrm{d}} \\
\left(\times 10^{3}\right)\end{array}$} & \multirow[b]{2}{*}{ Membrane $^{\mathrm{e}}$} & \multirow{2}{*}{$\begin{array}{l}\text { Density }^{\mathrm{f}} \\
\left(\mathrm{g} / \mathrm{cm}^{3}\right)\end{array}$} & \multirow{2}{*}{$\begin{array}{c}2 \theta^{\mathrm{g}} \\
(\mathrm{deg})\end{array}$} & \multicolumn{2}{|c|}{ Column diameter } & \multirow{2}{*}{$\begin{array}{l}\lambda_{\max }{ }^{\mathrm{k}} \\
(\mathrm{nm})\end{array}$} & \multirow[b]{2}{*}{$\log \varepsilon^{1}$} & \multirow[b]{2}{*}{ Ref } \\
\hline & & & & & & & & & & $\begin{array}{c}\text { WAXS }^{\mathrm{h}} \\
(\AA)\end{array}$ & $\begin{array}{c}\text { Calcd }^{\mathrm{j}} \\
(\AA)\end{array}$ & & & \\
\hline TMSOH & 0 & none & 100 & 1.3 & 1.7 & 7.6 & +++ & 0.962 & 5.8 & 17.6 & 16.2 & 401 & 3.4 & $2,6,13$ \\
\hline TMS1H & 1 & none & 83 & 2.5 & 1.4 & 5.7 & +++ & 1.008 & 4.4 & 23.2 & 25.0 & 454 & 3.9 & 2,6 \\
\hline TMS1PEH & 1 & $\mathrm{PhE}$ & 67 & 2.8 & 1.6 & 5.1 & +++ & 1.007 & 3.5 & 29.1 & 34.5 & $446^{\mathrm{m}}$ & $3.4^{\mathrm{m}}$ & 7,10 \\
\hline TMS1SiH & 1 & $\mathrm{PhSi}$ & 15 & 0.33 & 1.6 & 0.57 & + & 0.964 & & & 36.7 & 414 & 3.5 & 4 \\
\hline TMS1Si2H & 1 & $\mathrm{PhSi} 2$ & 65 & 0.11 & 2.2 & 0.16 & + & 1.026 & & & 41.3 & $455^{\mathrm{m}}$ & $3.5^{\mathrm{m}}$ & 4 \\
\hline TMS1Si2PEH & 1 & $\mathrm{PhSi} 2 \mathrm{PhE}$ & 35 & 9.6 & 1.7 & 12.8 & ++ & 1.038 & 3.3 & 30.9 & 49.4 & 424 & 3.5 & 5 \\
\hline TMS1Si4PEH & 1 & $\mathrm{PhSi} 4 \mathrm{PhE}$ & 21 & 3.2 & 1.7 & 3.5 & ++ & 1.040 & 2.8 & 36.4 & 59.1 & 439 & 3.6 & 5 \\
\hline TMS2H & 2 & none & 26 & 2.8 & 1.4 & 2.8 & ++ & 1.027 & 3.2 & 31.9 & 35.2 & 457 & 3.6 & 2,6 \\
\hline TMS2PEH & 2 & $\mathrm{PhE}$ & 26 & 0.41 & 1.5 & 0.38 & + & 1.010 & & & 40.9 & $460^{\mathrm{m}}$ & $3.2^{\mathrm{m}}$ & 10 \\
\hline TMS3H & 3 & $\mathrm{PhE}$ & 0.8 & 0.13 & 2.2 & 0.064 & - & & & & 44.9 & & & 6 \\
\hline $\mathrm{PMDSOH}$ & 0 & none & 58 & 0.76 & 1.9 & 3.1 & +++ & 0.988 & 5.2 & 19.6 & 20.4 & 412 & 3.6 & $6,7,14$ \\
\hline PMDS1H & 1 & none & 88 & 2.5 & 1.7 & 4.2 & +++ & 1.019 & 4.0 & 25.5 & 29.4 & 476 & 3.9 & 6,7 \\
\hline PMDS1PEH & 1 & $\mathrm{PhE}$ & 88 & 1.7 & 1.7 & 2.5 & +++ & 1.029 & 3.1 & 32.9 & 39.4 & 456 & 3.5 & 7,10 \\
\hline PMDS2H & 2 & none & 8 & 0.43 & 2.2 & 0.34 & + & & & & 50.6 & 489 & 3.7 & 6,10 \\
\hline PMDS2PEH & 2 & $\mathrm{PhE}$ & 20 & 0.85 & 1.7 & 0.61 & + & & & & 61.5 & 453 & 3.3 & 10 \\
\hline NMTSOH & 0 & none & 30 & 1.3 & 1.7 & 3.2 & +++ & $>1$ & 4.3 & 23.7 & 28.8 & 423 & 3.5 & $6,7,14$ \\
\hline NMTS1H & 1 & none & 94 & 4.2 & 1.6 & 4.7 & ++ & 1.014 & 3.2 & 31.9 & 39.1 & 484 & 3.8 & 6,7 \\
\hline NMTS1PEH & 1 & $\mathrm{PhE}$ & 92 & 4.1 & 1.4 & 4.2 & +++ & 1.021 & 2.4 & 42.5 & 49.2 & 463 & 3.7 & 7,10 \\
\hline NMTS2H & 2 & none & 4 & 0.30 & 4.0 & 0.16 & + & 1.031 & & & 60.2 & 495 & 3.7 & 6,10 \\
\hline $\mathrm{Hex} 0 \mathrm{H}$ & 0 & none & 49 & $5.3^{\mathrm{n}}$ & $5.2^{\mathrm{n}}$ & 2.6 & +++ & & & & & $420^{\mathrm{m}}$ & & 8 \\
\hline Hex1H & 1 & none & 35 & $8.2^{\mathrm{n}}$ & $3.0^{\mathrm{n}}$ & 1.6 & +++ & & & & & 455 & & 8 \\
\hline DB0H & 0 & none & 100 & & & & - & & & & & 463 & & $2,15,16$ \\
\hline DB1H & 1 & none & 79 & 0.56 & 1.3 & 1.1 & - & & & & & 478 & & 2 \\
\hline TMSP1H & 1 & & 46 & 0.46 & 1.5 & 1.2 & + & & & & 20.9 & 476 & & 4 \\
\hline TMSTPA1H & 1 & & 26 & 3.9 & 1.4 & 7.5 & +++ & 1.030 & 4.2 & 24.6 & 21.1 & $500^{\mathrm{m}}$ & $3.4^{\mathrm{m}}$ & 9,10 \\
\hline TMSTPA2H & 2 & & 10 & 0.94 & 1.5 & 0.90 & & & & & & & & 9 \\
\hline TMSTPAE2H & 2 & & 47 & 3.6 & 1.4 & 3.3 & + & 1.068 & 2.9 & 35.2 & 39.8 & 500 & & 9 \\
\hline PSTPA1H & 1 & & 24 & 3.2 & 1.6 & 4.9 & +++ & & & & & & & 11 \\
\hline EPHG & 1 & & 20 & $0.048^{\mathrm{n}}$ & $2.0^{\mathrm{n}}$ & 0.093 & - & & & & & $530^{\mathrm{m}}$ & $3.7^{\mathrm{m}}$ & 17,18 \\
\hline EPHG/TMSOH & 1 & & 71 & $0.48^{\mathrm{n}}$ & $3.0^{\mathrm{n}}$ & $1.9^{\mathrm{p}}$ & +++ & & & & & & & 17 \\
\hline MG0PA & 0 & & 60 & 0.92 & 1.4 & 3.4 & - & & & & & & & 8 \\
\hline HGOPA & 0 & & 87 & 2.4 & 1.8 & 5.9 & +++ & 1.062 & 3.3 & 33.1 & & $400^{\mathrm{m}}$ & & 8 \\
\hline DG0PA & 0 & & 65 & 2.8 & 2.7 & 4.9 & - & & & & & & & 8 \\
\hline HG1PA & 1 & & 92 & 6.1 & 1.7 & 7.4 & ++ & 1.068 & 3.1 & 35.2 & & 441 & & 8 \\
\hline
\end{tabular}

aToluene or chloroform, $[M]_{0}=0.2-0.5 \mathrm{~mol} / 1,[M]_{0} /\left[[\mathrm{Rh}(\mathrm{nbd}) \mathrm{Cl}]_{2}\right]_{0}=100$ to 5000 , $[\text { triethylamine }]_{0} /[\mathrm{cat}]_{0}=10-5000,25^{\circ} \mathrm{C}, 2 \mathrm{~h}$, precipitated with $\mathrm{MeOH}, \mathrm{MeOH} /$ benzene or hexane. ${ }^{\mathrm{b}} \mathrm{PhE}$ : phenyleneethynylene; $\mathrm{PhSi}$ : phenylene(dimethylsilylene); PhSi2: phenylene(tetramethyldisiloxanylene); PhSi2PhE: phenylene(tetramethyldisiloxanylene)phenyleneethynylene; PhSi4PhE: phenylene(octamethyltetrasiloxanylene)phenyleneethynylene. ${ }^{\mathrm{c}}$ Measured by GPC-LALLS with THF eluent at $40{ }^{\circ} \mathrm{C} .{ }^{\mathrm{d}} \mathrm{Calculated}$ from $M_{\mathrm{w}} \cdot{ }^{\mathrm{e}} \mathrm{Membrane}$ forming ability: - , poor; + , brittle; ++ , good; +++ , tough. ${ }^{f}$ Determined by floating method using $\mathrm{DMSO} / \mathrm{H}_{2} \mathrm{O}$ or $\mathrm{MeOH} / \mathrm{H}_{2} \mathrm{O}$. ${ }^{\mathrm{g}}$ Crystalline peak of the wide-angle X-ray scattering of the polymers. ${ }^{\mathrm{h}}$ Estimated from $2 \theta$ using $\mathrm{n} \lambda=2 d \sin \theta$ and Column diameter $=$ $2 d / \sqrt{3}$. ${ }^{\mathrm{j}}$ Estimated from molecular modeling for slightly distorted cis-transoidal conformation of poly(phenylacetylene) derivatives. ${ }^{\mathrm{k}}$ Visible absorption maxima in chloroform. ${ }^{1} \varepsilon\left(\mathrm{M}^{-1} \mathrm{~cm}^{-1}\right)$. ${ }^{\mathrm{m}}$ Shoulder peak. ${ }^{\mathrm{n}}$ Determined from GPC calibrated by polystyrene standard. ${ }^{\mathrm{p}}$ Calculated from the value of $22 \mathrm{~mol} \%$ EPHG in polymer.

dendrimer loading and chemical modification at the outer skin of polyimide membranes apparently reached equilibrium after an immersion time of more than $24 \mathrm{~h}$. On the other hand, the higher generation PAMAM dendrimers could only penetrate slightly because of the bigger molecular sizes. The gas permeability excluding solvent swelling effects decreased with crosslinking time, and the order of the gas permeability decrease $\left(\mathrm{CH}_{4}>\mathrm{N}_{2}>\mathrm{CO}_{2}>\mathrm{O}_{2}>\mathrm{He}\right)$ closed to the order of the Lennard-Jones diameter of gas molecules except for $\mathrm{CO}_{2}$. The decrease of gas permeability values were attributed to the crosslinking structure, the increased intersegmental interaction among the amide groups with the aid of hydrogen bonds, and the reduced free volume due to the space filling effect by dendrimers. The decrease of $\mathrm{CO}_{2}$ gas permeability was suppressed because of the strong interaction between $\mathrm{CO}_{2}$ and PAMAM dendrimers, and 


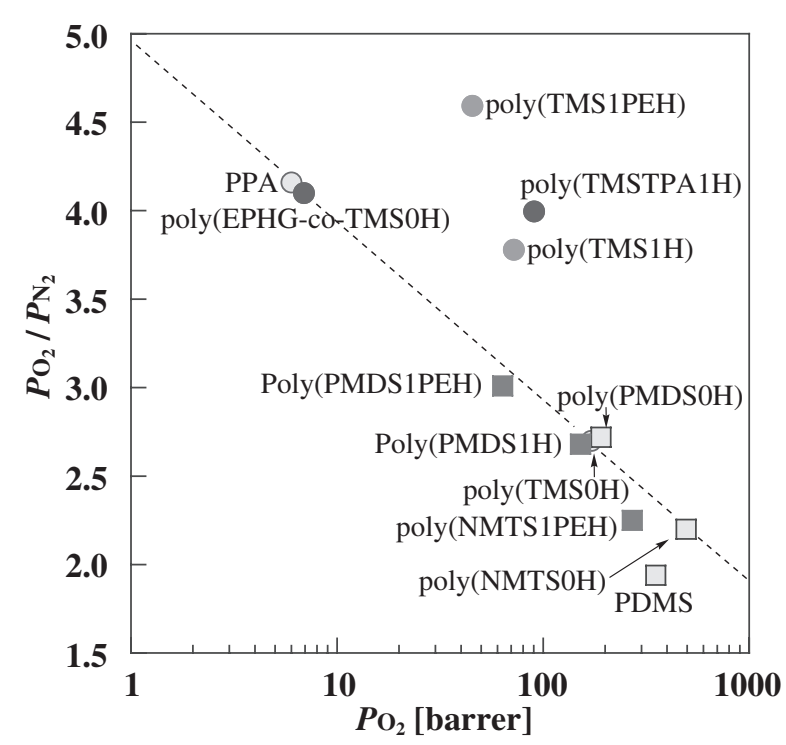

Figure 1. Permselectivity of poly(phenylacetylene) analogue membranes for $\mathrm{O}_{2} / \mathrm{N}_{2}$ separation. Poly(TMS1H) from ref 2, poly(TMS1PEH), poly(PMDS1H), poly(PMDS1PEH) and poly(NMTS1PEH) from ref 7, poly(TMSTPA1) from ref 10, poly(EPHG-TMSOH) from ref 17, poly(phenylacetylene) (PPA) and poly(TMSOH) form ref 13, poly(PMDSOH) and poly(NMTSOH) from ref 14, and poly(dimethylsiloxane) (PDMS) from ref 37. the ideal selectivity of PAMAM dendrimer modified polyimide membranes for both $\mathrm{CO}_{2} / \mathrm{CH}_{4}$ and $\mathrm{CO}_{2} /$ $\mathrm{N}_{2}$ are improved.

2.4.2. Closslinked Hyperbranched Polymers. Hyperbranched polymers have many branched units as same as dendrimers, although the shape-persistency of the hyperbranched polymers is less than that of the dendrimers. Therefore, the hyperbranched polymers may be considered as the polymers linking various generations of dendrimers. Hyperbranched polyimide membranes were prepared from triamine monomers and diphthalic anhydrides. ${ }^{23-25}$ Amineterminated hyperbranched polyimides were synthesized by condensation polymerization of tris(4-aminophenyl)amine (TAPA) and diphthalic anhydrides as shown in Scheme 4, and the obtained polyimides were treated with crosslinking agents such as ethylene glycol diglycidyl ether (EGDE) and terephtaldehyde (TPA) to give the hyperbranched polyimide membranes. ${ }^{23}$ TPA-crosslinked 6FDA-TAPA membranes with low crosslinking content showed high gas permeability coefficient $\left(P_{\mathrm{CO}_{2}}=65, P_{\mathrm{O}_{2}}=11, P_{\mathrm{N}_{2}}=\right.$ 2.16 and $P_{\mathrm{CH}_{4}}=1.59$ barrer) and high permselectivity $\left(\alpha_{\mathrm{CO}_{2} / \mathrm{N}_{2}}=30, \alpha_{\mathrm{CO}_{2} / \mathrm{CH}_{4}}=41\right.$ and $\left.\alpha_{\mathrm{O}_{2} / \mathrm{N}_{2}}=5.0\right)$

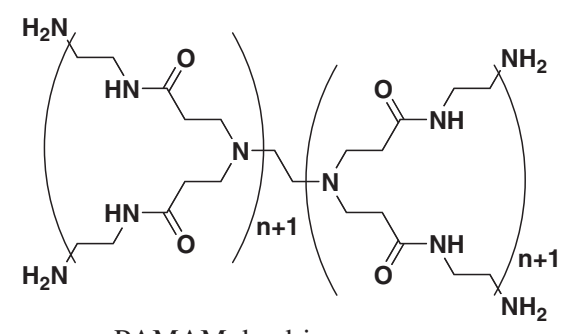

PAMAM dendrimer $\mathrm{n}$ : generation number

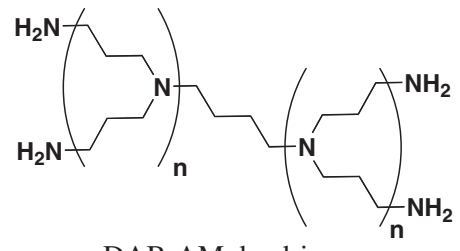

DAB-AM dendrimer $\mathrm{n}$ : generation number<smiles>Cc1c(C)c(C)c(N2C(=O)c3ccc(C(c4ccc5c(c4)C(=O)N(C)C5=O)(C(F)(F)F)C(F)(F)F)cc3C2=O)c(C)c1C</smiles>

6FDA-durene

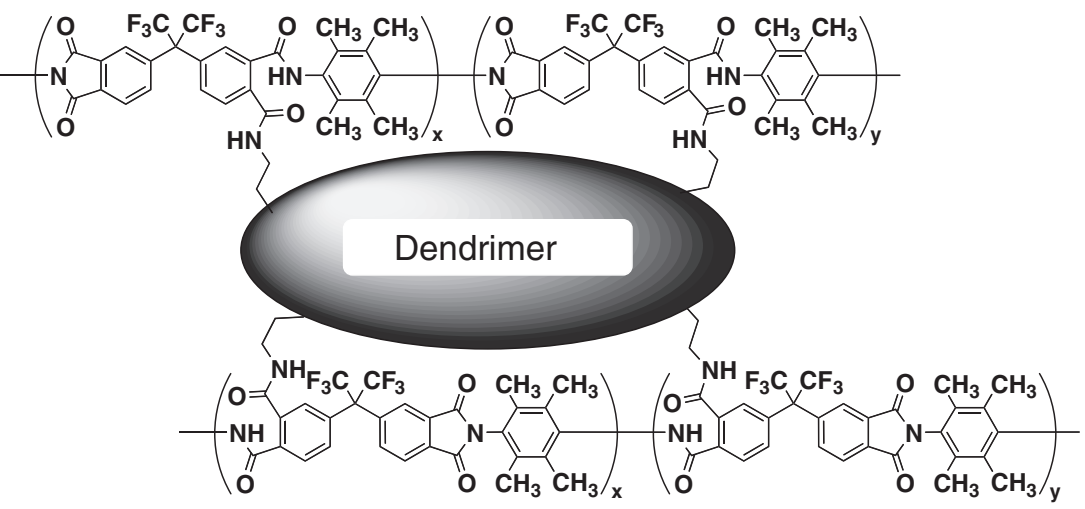

Dendrimer crosslinked modification

Scheme 3. 


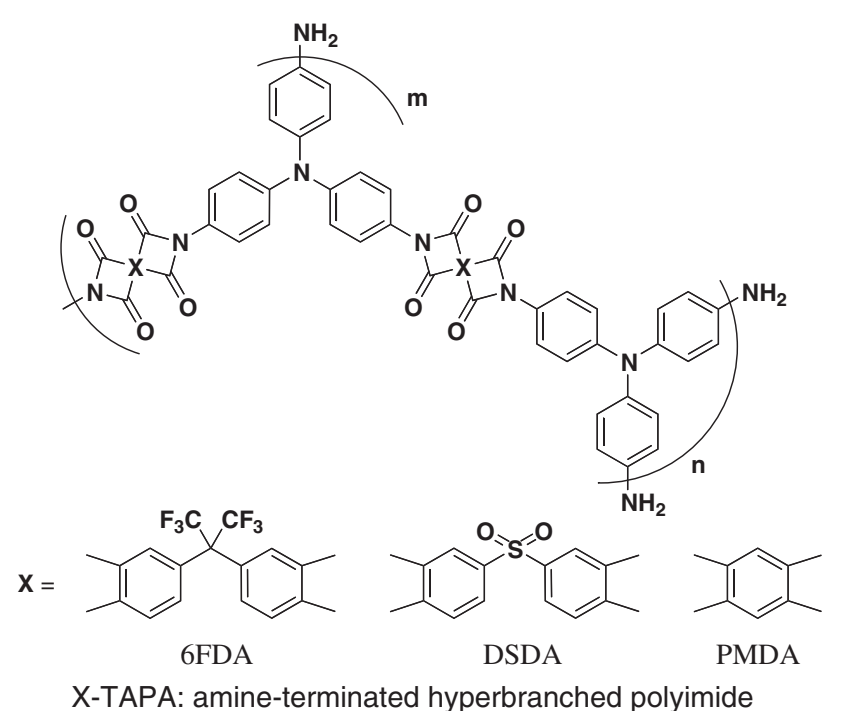

X-TAPA: amine-terminated hyperbranched polyimide

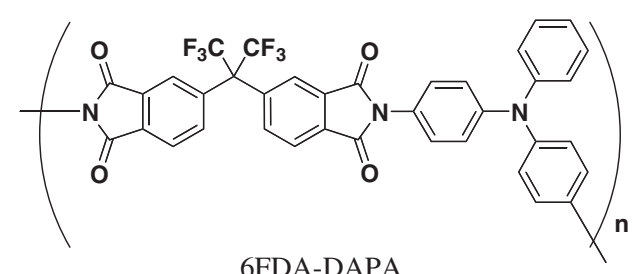

Scheme 4.

compared with linear polyimide membranes (6FDADAPA: $P_{\mathrm{CO}_{2}}=23, P_{\mathrm{O}_{2}}=6.0, P_{\mathrm{N}_{2}}=1.12$ and $P_{\mathrm{CH}_{4}}=$ 0.68 barrer; $\alpha_{\mathrm{CO}_{2} / \mathrm{N}_{2}}=20, \alpha_{\mathrm{CO}_{2} / \mathrm{CH}_{4}}=34$ and $\alpha_{\mathrm{O}_{2} / \mathrm{N}_{2}}=$ 4.8). The anhydride-terminated hyperbranched polyimide was also synthesized, and amine-terminated poly(ethylene oxide) (PEO) was grafted on the peripheral anhydrides to give a star-like PEO. ${ }^{24}$ The star-like PEO membrane was obtained via crosslinking with EGDE. However, $\mathrm{CO}_{2} / \mathrm{N}_{2}$ permselectivity of the star-like PEO membrane was not improved because of a larger content of intermediate phases containing hyperbranched polyimide and PEO segments.

The other hyperbranched polyimide membrane was prepared via casting the corresponding polyamic acid solution which was synthesized from 1,3,5-tris(4aminophenoxy)benzene (TAPOB) and 4,4'-(hexafluoroisopropylidene) diphthalic anhydride (6FDA) as shown in Scheme 5. ${ }^{25}$ The fractional free volume (FFV) of hyperbranched polyimide 6FDA-TAPOB was higher than that of linear polyimide 6FDA-TPEQ and 6FDA-TPER due to looser packing of molecular chains of the 6FDA-TAPOB attributed to the characteristic hyperbranched structure. Gas permeability of 6FDA-TPER $\left(P_{\mathrm{CO}_{2}}=5.13, P_{\mathrm{O}_{2}}=1.04, P_{\mathrm{N}_{2}}=0.156\right.$ barrer) was lower than that of 6FDA-TPEQ $\left(P_{\mathrm{CO}_{2}}=\right.$ 12.6, $P_{\mathrm{O}_{2}}=2.24, P_{\mathrm{N}_{2}}=0.371$ barrer) because of the lower diffusivity of 6FDA-TPER attributed to both the lower FFV and the increased inhibition to the segmental mobility, beside its higher selectivity (6FDA-
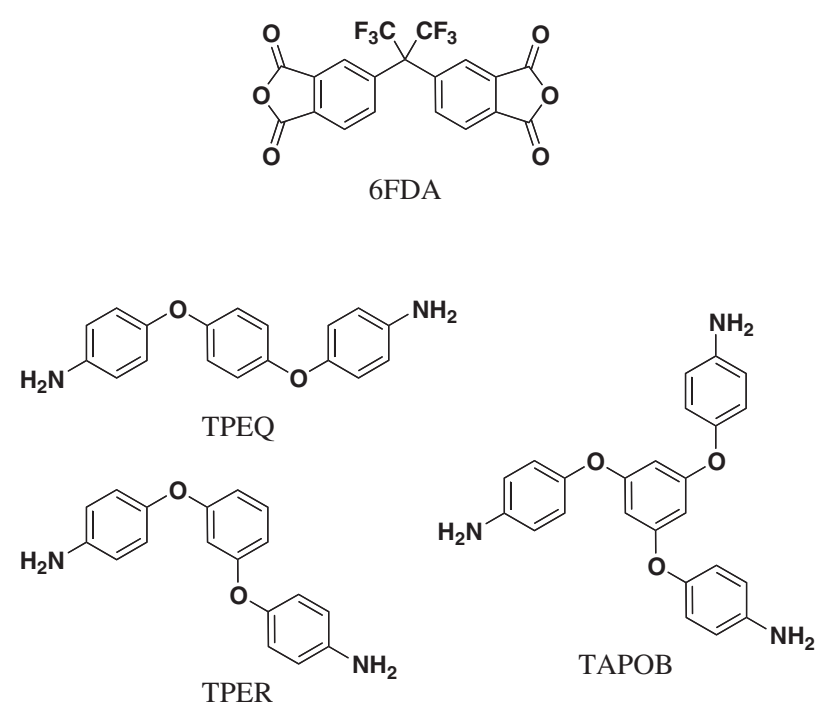

Scheme 5.

TPER: $\alpha_{\mathrm{O}_{2} / \mathrm{N}_{2}}=6.65$, 6FDA-TPEQ: $\left.\alpha_{\mathrm{O}_{2} / \mathrm{N}_{2}}=6.03\right)$. On the other hand, hyperbranched polyimide 6FDATAPOB showed high gas permeability $\left(P_{\mathrm{CO}_{2}}=12.8\right.$, $P_{\mathrm{O}_{2}}=2.25, P_{\mathrm{N}_{2}}=0.363$ barrer) due to the higher FFV, but had higher permselectivity $\left(\alpha_{\mathrm{O}_{2} / \mathrm{N}_{2}}=6.21\right)$ than 6FDA-TPEQ. This behavior was explained as follows: low segmental mobility and unique size and distribution of free volume holes arising from the characteristic hyperbranched structure of 6FDATAPOB provided effective $\mathrm{O}_{2} / \mathrm{N}_{2}$ selectivity in comparison with 6FDA-TPEQ.

\subsection{Dendrimers Supported by Membranes}

2.5.1 Star Polymers Physically Supported by Membranes. Although star polymers are usually different from dendrimers, the star polymers consisting of graft polymers can be considered as G1 dendrimers. The six armed star polymer with cyclophosphazene core was synthesized, and triethylene glycol monomethyl ether side chains were grafted on its $3 \alpha$-helix bundle poly(L-glutamate) arms. ${ }^{26}$ The membrane of the obtained polymer was fabricated onto a porous Teflon support. Enantioselective permeation of Trp, Tyr and Phe was achieved for the composite membrane in comparison with the membrane prepared from conventional linear polyglutamate. This behavior was explained as follows: the short oxyethylene chains around hexaarmed polyglutamate could assemble side to side to form relatively narrow channel along the $\alpha$-helical, and this narrow channel made possible molecular recognition of racemates in the vicinity of $\alpha$-helical polyglutamate backbone.

2.5.2 PAMAM Dendrimers Attached on Membranes. PAMAM dendrimer (Scheme 3) ultrathin membranes were prepared by the repetition of the immersion of the substrate in methanol solution 
containing amine-terminated PAMAM dendrimer $\left(\mathrm{Gn}-\mathrm{NH}_{2}\right)$ and reaction with poly(maleic anhydrideco-methylvinylether) $(\mathrm{Gz}){ }^{27,28}$ The ultrathin membrane supported by a Au-coated Si wafer electrode showed $\mathrm{pH}$-switchable permselectivity for both cationic and anionic redox-active probe molecules. ${ }^{27}$ The ionic permeability was investigated by cyclic voltammograms of the electrode modified with the G4- $\mathrm{NH}_{2} / \mathrm{Gz} / \mathrm{G} 4-\mathrm{NH}_{2} / \mathrm{Gz} / \mathrm{G} 4-\mathrm{NH}_{2}$ membrane which was prepared via three times immersion in G4 PAMAM dendrimer solution, and it was found that $\mathrm{Fe}(\mathrm{CN})_{6}{ }^{3-}$ and $\mathrm{Ru}\left(\mathrm{NH}_{3}\right)_{6}{ }^{3-}$ penetrated at $\mathrm{pH} 3.0$ and $\mathrm{pH} 11.0$, respectively. The $\mathrm{G} 4-\mathrm{NH}_{2} / \mathrm{Gz} / \mathrm{G} 4-\mathrm{NH}_{2} /$ $\mathrm{Gz} / \mathrm{G} 4-\mathrm{NH}_{2}$ membranes were $24 \mathrm{~nm}$ thick, and rejected the permeation of $\mathrm{Fe}(\mathrm{CN})_{6}{ }^{3-}$ and $\mathrm{Ru}\left(\mathrm{NH}_{3}\right)_{6}{ }^{3-}$ at $\mathrm{pH} 11.0$ and $\mathrm{pH}$ 3.0, respectively, ("Off" state). However, the G4- $\mathrm{NH}_{2} / \mathrm{Gz} / \mathrm{G} 4-\mathrm{NH}_{2}$ membranes with $14 \mathrm{~nm}$ thick, which was prepared via two times immersion in G4 PAMAM dendrimer solution, leaked to a much greater extent than the $\mathrm{G} 4-\mathrm{NH}_{2} / \mathrm{Gz} / \mathrm{G} 4-\mathrm{NH}_{2} /$ $\mathrm{Gz} / \mathrm{G} 4-\mathrm{NH}_{2}$ membrane at "Off" state. Nanoporous alumina substrate (pore number content: $3.8 \times 10^{3}$ pores $/ \mu \mathrm{m}^{2}$, diameter: $6.8 \pm 4.8 \mathrm{~nm}$ ) was modified with the G6- $\mathrm{NH}_{2} / \mathrm{Gz} / \mathrm{G} 6-\mathrm{NH}_{2}$ membranes with $12 \mathrm{~nm}$ thick. ${ }^{28}$ The naked nanoporous alumina substrate showed adsorption of volatile organic compounds (heptane, benzene, dichloromethane and ethanol) onto its pore walls. On the other hand, for the nanoporous alumina substrate modified with the G6- $\mathrm{NH}_{2} / \mathrm{Gz} / \mathrm{G} 6-$ $\mathrm{NH}_{2}$ membranes, the permeation of volatile organic compounds was almost completely shut off in spite of $12 \mathrm{~nm}$ thick of the G6- $\mathrm{NH}_{2} / \mathrm{Gz} / \mathrm{G} 6-\mathrm{NH}_{2}$ membranes.

2.5.3 PAMAM Dendrimers Attached on SurfaceModified Membranes. In order to improve the adhesion between a dendrimer layer and a substrate surface, surface-modified membranes were reported. ${ }^{29,30}$ The surface of PDMS substrate was modified by plasma treatment either in air or in maleic anhydride vapor, and then G4 PAMAM dendrimer in methanol was cast onto the PDMS substrate to give G4 PAMAM dendrimer modified membrane (PDMS-D: plasma-modified in air, PDMS-AH-D: plasma-modified in maleic anhydride vapor) ${ }^{29}$ Surface characterization was carried out using XPS, ATR FT-IR and contact-angle. The surface coverage of dendrimer for PDMS-D was $82.2 \%$ for the dendrimer loading of $40 \mu \mathrm{g} / \mathrm{cm}^{2}$, and the dendrimer layer did not exceed $0.6 \mu \mathrm{m}$ for the dendrimer loading of $60 \mu \mathrm{g} / \mathrm{cm}^{2}$. Propane permeation of PDMS-D was investigated, and it decreased with increasing amounts of loaded dendrimer. For PDMS-AH-D containing $\mathrm{AgBF}_{4}$, permselectivity of propylene/propane was examined. PDMS$\mathrm{AH}-\mathrm{D}$ could be loaded $\mathrm{AgBF}_{4}$ more than the surfacemodified membrane without dendrimer, and show good propylene permeability and propylene/propane selectivity due to the extra loading capability of silver salts by the dendrimer molecules. G4 PAMAM dendrimer-immobilized membrane was prepared from polypropylene substrate whose surface was modified by plasma treatment in maleic anhydride vapor. ${ }^{30}$ Oxygen gas permeation measurement of the obtained membrane showed improvement in the gas barrier compared to the untreated polypropylene membrane.

2.5.4 Hyperbranched PAA and PAMAM Dendrimer on a Gold-Coated Porous Alumina. Gold-coated porous alumina was used as the substrate because alkyl thiol was able to form a self-assembled monolayer on a gold surface. ${ }^{31,32}$ Hyperbranched poly(acrylic acid) (PAA) thin membrane was fabricated on a gold-coated porous alumina, whose surface was modified by a self-assembled monolayer of a carboxylic acid-terminated thiol, by the repetition of the graft of $\alpha, \omega$-diamino-terminated poly(tert-butyl acrylate) and elimination of tert-butyl groups. ${ }^{31}$ Six layer hyperbranched PAA membrane had about $940 \AA$ thick, and field-emission scanning electron microscopy (FESEM) and AFM images clearly showed that the hyperbranched PAA membrane completely covered the substrate surface without filling underlying pores. The gas permeability of 3-6 layer hyperbranched PAA membranes were investigated for $\mathrm{He}, \mathrm{CH}_{4}, \mathrm{~N}_{2}$, $\mathrm{O}_{2}, \mathrm{CO}_{2}$ and $\mathrm{SF}_{6}$, and 3-5 layer hyperbranched PAA membranes showed modest Knudsen diffusion-based selectivity, while the gas permeability of six layer hyperbranched PAA membrane was not observed. The three layer hyperbranched PAA membrane modified by $\mathrm{H}_{2} \mathrm{NCH}_{2}\left(\mathrm{CF}_{2}\right)_{6} \mathrm{CF}_{3}$ improved $\mathrm{He}, \mathrm{O}_{2}$ and $\mathrm{CO}_{2}$ permeability. A gold-coated porous alumina modified by a self-assembled monolayer of a mercaptopropionic acid were treated with alternating adsorption of protonated G4 PAMAM dendrimer and ionized PAA to give PAMAM/PAA multilayer membranes. ${ }^{32}$ Although the gas permeability of PAMAM/PAA 4.5 layer membrane was investigated in comparison with that of poly(allylamine hydrochloride)/PAA bilayer membrane, the reproducible gas permeation data was not able to be taken. ${ }^{33}$

2.5.5 PAMAM Dendrimer-Liquid Membranes Contained in the Pores of Porous Membranes. Some liquid membranes using porous membranes containing dendrimers in the pores were reported. ${ }^{34-36} \mathrm{~A}$ dendrimer membrane was prepared by the immersion of porous a hydrophilized polyvinylidene fluoride flat membrane (porosity 0.7 ; pore size $0.1 \mu \mathrm{m}$; thickness $100 \mu \mathrm{m}$; tortuosity 2.58; Millipore) into pure G0 PAMAM dendrimer or glycerol solution of G0 PAMAM dendrimer. ${ }^{34,35}$ The $\mathrm{CO}_{2} / \mathrm{N}_{2}$ permeation performance through the liquid membranes was measured under various humidity. The separation factor $\alpha_{\mathrm{CO}_{2} / \mathrm{N}_{2}}$ was almost 19000 at a low $\mathrm{CO}_{2}$ partial pres- 
sure $\left(\Delta p_{\mathrm{CO}_{2}}=0.36 \mathrm{cmHg}\right)$ under the completely humidified condition, while it was around 700 at the higher $\Delta p_{\mathrm{CO}_{2}}(>30 \mathrm{cmHg})$. The separation factor $\alpha_{\mathrm{CO}_{2} / \mathrm{N}_{2}}$ decreased depending on the decrease of humidity because the permeability of $\mathrm{N}_{2}$ through the G0 PAMAM dendrimer liquid membrane was extraordinarily low when the feed gas was humidified. However, dendrimer solution of $75 \%$ in glycerol improved $\alpha_{\mathrm{CO}_{2} / \mathrm{N}_{2}}$ at the lower humidity, which corresponded to the fact that glycerol absorbed much more water than the pure dendrimer liquid. When the glycerol carbonate was used instead of glycerol, the $\mathrm{CO}_{2} / \mathrm{N}_{2}$ permeation indicated the better performance due to its high viscosity and high boiling point, and the $\mathrm{CO}_{2}$ selective behavior of glycerol carbonate was not affected by the absence of moisture in the feed gas mixture. ${ }^{36}$ Addition of small amounts of G0 PAMAM dendrimer to the glycerol carbonate liquid membrane appeared to significantly help $\mathrm{CO}_{2}$ facilitation at low $\mathrm{CO}_{2}$ partial pressures.

\section{ENANTIOSELECTIVELY PERMEABLE MEMBRANES FROM ONE-HANDED HELICAL POLYMERS}

\subsection{Classification of Permselective Membranes}

There are many kinds of permselective membranes, which can be classified by the size of permeating path. When the paths are fixed and the sizes are big, they are named porous membranes whose chemical structures are not important and only the sizes are a decisive factor for the permselectivities. When the sizes are small and the paths are dynamic like free volume between molecules, they are classified nonporous membranes or dense membranes whose chemical structures are very important for the permselectivities.

\subsection{Importance for the Control of Chemical Structures}

To separate the mixture of small particles like molecules, the latter membranes i.e., nonporous membranes or dense membranes are necessary. Therefore, to separate enantiomers whose sizes are identical, the precise control of the chemical structures of the membrane polymers is important. In this case, polymer synthesis and macromolecular design become key technology and science. According to this hypothesis, we have been synthesizing new chiral polymers for nonporous or dense membranes.

\subsection{Classification of Enantioselectively Permeable Membranes}

Several kinds of enantioselectively permeable membranes have been reported. These are divided into four categories as follows: 1) application of known chiral hosts (3.4), 2) application of polymers used for chiral stationary phases in HPLC (3.5), 3) application of the molecular imprinting method $(3.6), 4)$ synthesis of new chiral polymers (3.7).

Before our macromolecular designs of new onehanded helical polymers for enantioselectively permeable membranes are discussed in 3.7 , some examples of enantioselectively permeable membranes reported are described briefly in 3.4-3.6.

3.4 Introduction of Known Chiral Hosts such as Chiral Crown Ethers, Enzymes, and Other Biopolymers as Carriers to Supporting Membranes such as Liquid Membranes and Porous Membranes

There are many chiral hosts which can discriminate enantiomers. For example, there are artificial compounds such as chiral crown ethers, and biopolymers such as cyclodextrins, DNA, and enzymes. As most of chiral hosts have no membrane forming abilities, supporting membranes such as liquid membranes and porous membranes should be used. It is important how effectively the carriers are incorporated into supporting membranes with maintaining their recognition abilities. In these composite membranes, membrane materials themselves have no ability to discriminate permeants because they functioned as only supporting membranes.

3.4.1 Chiral Crown Ethers. It is famous that Cram et al. used chiral crown ethers which can recognize enantiomers as a mobile carrier in a liquid membrane. ${ }^{38}$ It showed high enantioselectivity but low durability because the loss of the liquid and carriers could not be avoided. After that, many related researches were reported to improve the low stability of the liquid based membrane. Yamaguchi et al. stabilized the liquid membrane by using porous membranes maintaining the mobility of the carrier. ${ }^{39}$ Kajiyama et al. also reported the introduction of the chiral crown ether to a liquid crystalline-polymer composite membrane without losing the mobility. ${ }^{40}$ On the other hand, Kakuchi et al. fixed chiral crown ethers to a polymeric membrane and observed enantioselective permeation. The permeation of the L-isomer which was complexed selectively by the crown ether was suppressed. Since the carrier is not mobile but fixed, the saturation phenomenon occurred. ${ }^{41}$

3.4.2 Chiral Copper Complexes. Clark et al. used $\mathrm{N}$-decyl-L-hydroxyproline-copper(II) complex as a mobile carrier in a supported liquid membrane. ${ }^{42}$ Pickering et al. used the same chiral copper complex in an emulsion liquid membrane. ${ }^{43}$

3.4.3 Cyclodextrin. Cyclodextrin was also reported to be introduced to permselective membranes as a chiral carrier. Keizer et al. impregnated a porous ceramic membrane with a cyclodextrin polymer. The membrane also reached saturation. ${ }^{44}$ Breytenbach et 
al. used cyclodextrin as a mobile carrier in a bulk liquid membrane. ${ }^{45}$ Ishihara et al. incorporated cyclodextrin to a polymeric membrane as a fixed carrier. The permeation of the D-isomer which was included selectively by the cyclodextrin was suppressed. In this case, the saturation occurred also. ${ }^{46}$ Long et al. also reported application of cyclodextrin to permselective membrane. ${ }^{47}$

3.4.4 DNA. Needless to say, the main function of DNA is maintenance and transfer of genetic information. In addition, the biological macromolecule is chiral. Higuchi et al. immobilized DNA in ultrafiltration membranes, observed enantioselective permeation, and categorized the composite membranes as channel type membranes. ${ }^{48-50}$

3.4.5 Proteins. Albumin which is one of carrier proteins in the blood was applied to optical resolution membranes by Higuchi et al. They combined the enantioselective recognition by albumin and ultrafiltration of L-isomer-albumin complexes. The composite membrane showed D-isomer selective permeation. ${ }^{51,52}$ Saito et al., immobilized albumin on a pore surface of a porous polymer membrane. ${ }^{53}$

3.4.6 Antibodies. Antibodies are proteins having molecular recognition ability. Martin et al. attached an antibody to the inner walls of silica nanotubes which was chemically synthesized within pores of an alumina membrane. The membranes selectively transport the enantiomer that specifically binds to the antibody. The enantioselectivity increased as the inside diameter of the silica nanotubes decrease because diffusional transport of the unwanted species was shut down. ${ }^{54}$

3.4.7 Enzymes. Enzymes selectively recognize and bind their substrate molecules. In addition, since enzymes are catalysts, they catalyze chemical reaction on the substrates molecules. Giorno et al. immobilized Lipase in a membrane of a polyamide and observed optical resolution and permeation together with a chemical reaction, hydrolysis. ${ }^{55}$ If enzymes are applied to permselective membrane process without reaction, these unwanted chemical reaction should be eliminated. Martin et al. used apoenzymes as molecular recognition agents. The apoenzyme was physically trapped within pores of a microporous polycarbonate membrane. The both ends of the pores were blocked by polypyrrole membranes. Therefore, the carrier was mobile. The D-isomer which was enantioselectively binded by the apoenzyme permeated predominantly. ${ }^{56}$ Retey et al. used "mutants" of enzymes which maintained their binding affinity for their substrates, but lost almost all catalytic activity. They also trapped the carrier physically, and therefore, the movement of the carrier was possible. ${ }^{57}$

Goto et al. applied some enzyme reactions to permselective membrane. For example, they incorporated an enzyme for enantioselective esterification in a liquid membrane and the other enzyme for ester hydrolysis in the permeate side. ${ }^{58-60}$

\subsection{Application of Polymeric Materials Used as Chi- ral Stationary Phases in HPLC to Permselective Membranes}

Many chiral stationary phases for HPLC were reported and several of them are practically used. Many researches about application of these chiral polymeric materials for HPLC to membranes have been reported.

3.5.1 Polysaccharides. Yashima et al. applied one of the derivatives of polysaccharides which is commercially available as a HPLC column to enantioselective permeation process. The enantioselectivity of the permeation process was based on enentioselective absorption and desorption. ${ }^{61,62}$ Kakuchi et al. synthesized a graft copolymer having polysaccharides as grafts and found enantioselective permeability of its membrane. D-isomer which was more weakly adsorbed permeated faster. ${ }^{63}$

3.5.2 Poly(amino acids) Derivatives. Maruyama et al. synthesized poly $(\gamma$-methyl L-glutamate)(PMLG) having rigid substituents which can make a liquid crystalline phase and found high enantioselective permeability through the membrane from the polymer and a supporting porous membrane. ${ }^{64} \mathrm{We}$ synthesized a PMLG derivative having flexible substituents which had self-membrane-forming ability. In this case, the permeability of D-isomer was suppressed because the interaction of the isomer with the polymer was stronger than that of L-isomer. ${ }^{65}$ Inoue et al. synthesized a new star polymer having six arms of PMLG and prepared a composite membrane of this polymer and a porous poly(tetrafluoroethylene) membrane where channels were formed. ${ }^{26} \mathrm{Jacobs}$ et al. also reported PMLG derivatives for permselective membranes. ${ }^{66}$ Satoh et al. used cross-linked poly(L-glutamic acid) for optical resolution. ${ }^{67}$ Masawaki et al. prepared a composite membrane from an oligomer from L-amino acids and a porous membrane and observed their enantioselective permeation. The suppression of permeation of L-isomer which has stronger interaction with the membrane was observed. ${ }^{68}$

\subsection{Application of the Molecular Imprinting Method (MIP) Where Chiral Compounds are Used as Guest Molecules to Permselective Membranes}

The molecular imprinting method (MIP) can produce molecular recognition sites relatively easier than synthetic method. The recognition site was produced during cross-linking polymerization in the presence of guest molecules. By using the method, some polymeric materials for chiral HPLC stationary phases have been prepared. Recently, a few examples of 
permselective membranes prepared by the MIP method were reported. Martin et al. reported the guest molecule-selective permeation(not enantioselective). ${ }^{69}$

Haupt et al. reported possibility of template-enantiomer-selective permeation. ${ }^{70}$ Yoshikawa et al. reported first the application of the MIP method to enantioselective membranes. They prepared the MIP membranes during not polymerization but membrane fabrication. ${ }^{71-73}$ Donato reported enantioselective permeation in a MIP membrane. A template isomer permeated predominantly. ${ }^{74}$

3.7 Macromolecular Design of Polymeric Materials for Enantioselectively Permeable Membranes, that is, Synthesis of New Chiral Polymers for Enantioselectively Permeable Membranes

3.7.1 Requirements for the Macromolecular Architectures of New Polymers for Enantioselective Membranes. As we described above in 3.4-3.6, preparation of many kinds of enantioselective membranes have been attempted. Most of them were transfer of known technology in the area of molecular recognition and HPLC to membrane technology. Therefore, it was focused on how effectively apply the materials used for carriers and HPLC stationary phases to membrane processes. Since most of them have no selfmembrane-forming ability, they need supporting membranes. In this approach, we think there are three main problems to overcome when we consider their possibility for practical use. The first one is the saturation for fixed carriers and the second one is unwanted nonselective permeation (diffusion) through the domains having no recognition ability. In addition, solid membranes are promising for practical use. Although the saturation problem has been solved by using mobile carriers in liquid membranes, the stability of the membrane is low and therefore not practical. Therefore, using carrier is thought to be not appropriate for practical use and continuous fixed carriers, i.e., channels seem to be more promising. To eliminate the domain having no recognition ability, it is needed to maximize the content of the recognition sites and remove all kinds of defects. To realize them, we have designed the macromolecular architectures and properties of new polymers for enantioselective membranes. We thought the following properties were necessary for the polymers.

1) The polymers have high content of chiral structures to enhance the content of the chiral recognition sites.

2) The polymers have self-membrane-forming ability to eliminate the domain and defects having no recognition ability.

3.7.2 The Reason Why We Selected Poly(substituted acetylene)s for Enantioselectively Permeable Mem- branes. We synthesized many kinds of new polymers by homopolymerization of new monomers for enantioselective membranes. Most of them were poly(substituted acetylene)s, especially poly(substituted phenylacetylene)s. The reasons why we selected them are follows.

1) Many substituted acetylenes can polymerize to yield soluble and high molecular weight polymers even if the monomers bear bulky groups. Therefore, they have self-membrane-forming ability.

2) Chiral substituted acetylenes can polymerize to yield one-handed helical polymers. Therefore, the membranes can have high content of a chiral structure.

3.7.3 One-Handed Helical Poly(disubstituted acetylene)s for Enantioselectively Permeable MembranesThe Effect of Content of the Chiral Group on the Enantioselectivity -. We reported that poly(pinanyldimethylsilylpropyne) (poly(PSP) in Figure 2) had self-membrane-forming ability and the membranes from only the polymer showed enentioselective permeation for many kinds of racemates. In particular, the enantioselectivity was almost $100 \%$ in the initial period (Figure 3). The polymer powder had no enantioselectivity in adsorption and the enantioselectivity appeared only in permeation (diffusion) through the pure membrane. ${ }^{75-78} \mathrm{We}$ also synthesized other chiral poly(disubstituted acetylene)s such as poly(2-methylbutyldimethylsilylpropyne) (poly(BSP) in Figure 2), and poly(diphenylacetylene)s having bulky chiral pinanyl groups or small chiral 2-methylbutyl groups (poly(PDPA) and poly(BDPA) in Figure 2) and observed their enantioselective permeation. ${ }^{79-81}$ The results of the ensntioselective permeation of these polymeric membranes were shown in Figure 2. As the permeation rates increased, the enantioselectivity decreased (Figure 3). Polymeric membranes with higher content of the chiral group showed higher enantioselectivities and lower permeation rates (The content was shown in the parentheses in Figure 2.). In the case of copolymers of chiral pinanyldimethylsilylpropyne with achiral trimethylsilylpropyne, when only the small amounts of the achiral groups were introduced, the enantioselectivity decreased abruptly as shown in Figure 4 . These findings show that high content of chiral groups and homogeneity of the chiral groups in the membrane were important for attaining high permselectivity. In general, the enantioselectivity of poly(diphenylacetylene)s were lower than that of poly(silylpropyne)s. This may be because the content of chiral groups of poly(diphenylacetylene)s were lower because they have two benzene groups, and the membranes of poly(diphenylacetylene)s may have some defects in the membranes due to the very rigid 

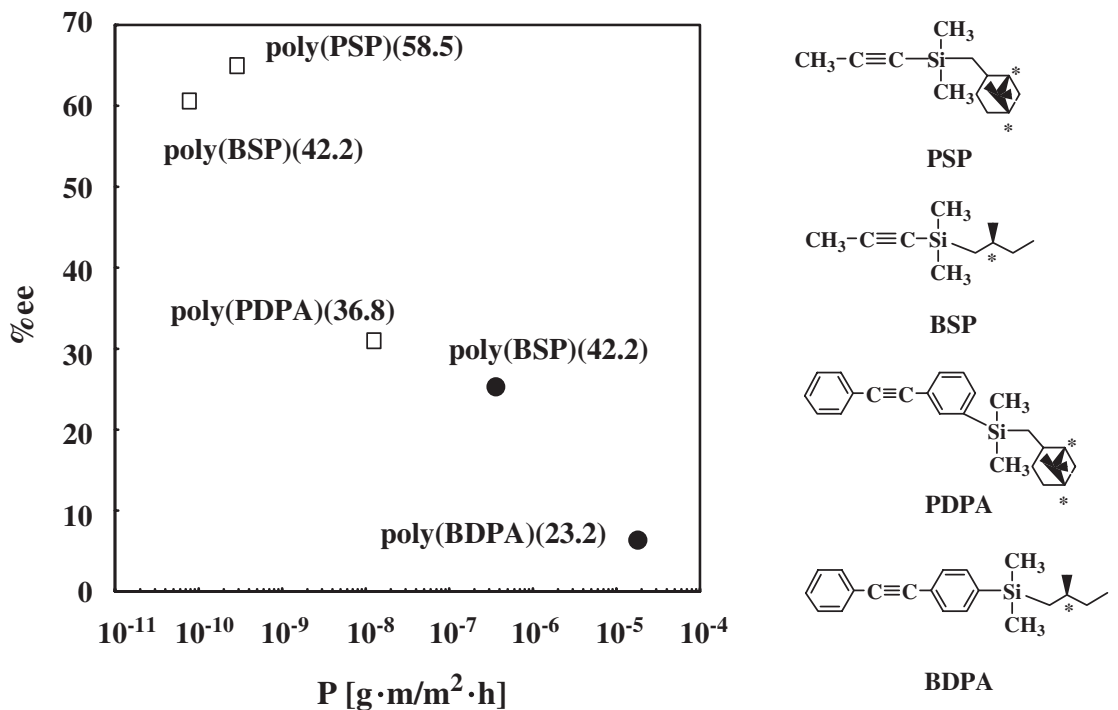

Figure 2. Plots of \%ee in the permeate $v s$. permeation rate (P) for racemic solutions of tryptophan ( $\square$, concentration-driven permeation) or 1,3-diacetoxybutane (, pervaporation) through mambranes of poly(disubstituted acetylene)s. The values in the parentheses are the content $(\mathrm{wt} \%)$ of the chiral group in the polymer (= membrane).

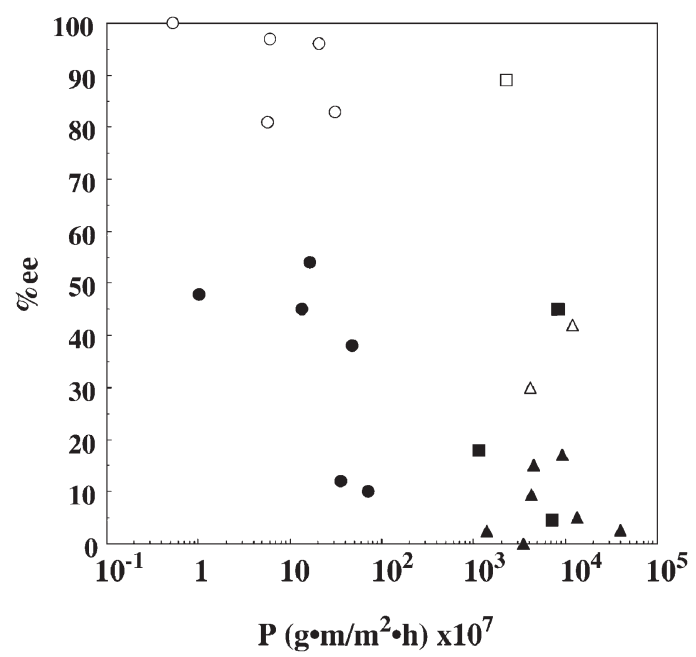

Figure 3. Plots of \%ee in the permeate $v$ s. permeation rate $(\mathrm{P})$ for various racemates. Circle symbol: concentration-driven permeation, triangular symbol: evapomeation, square symbol: pervaporation, open symbol: an initial period, solid symbol: after the period (Reprinted with permission from ref 76. Copyright 1996, American Chemical Society, Washington, DC.).

backbones. The degree of the bulkiness was not more important for permselectivity than the content of the chiral groups in the membrane. Although these chiral poly(disubstituted acetylene)s had a one-handed mainchain, the effect on the permselectivity was not clear.

3.7.4 One-Handed Helical Poly(phenylacetylene)s Having Bulky Chiral Groups as Pendants for Enantioselectively Permeable Membranes-The Effect of Content of the Chiral Group and the One-Handed Helical Main-Chain on the Enantioselectivity-. We synthesized new poly(phenylacetylene)s having oligopinanylsiloxanes as side groups (Figure 5) ${ }^{82-84}$ The

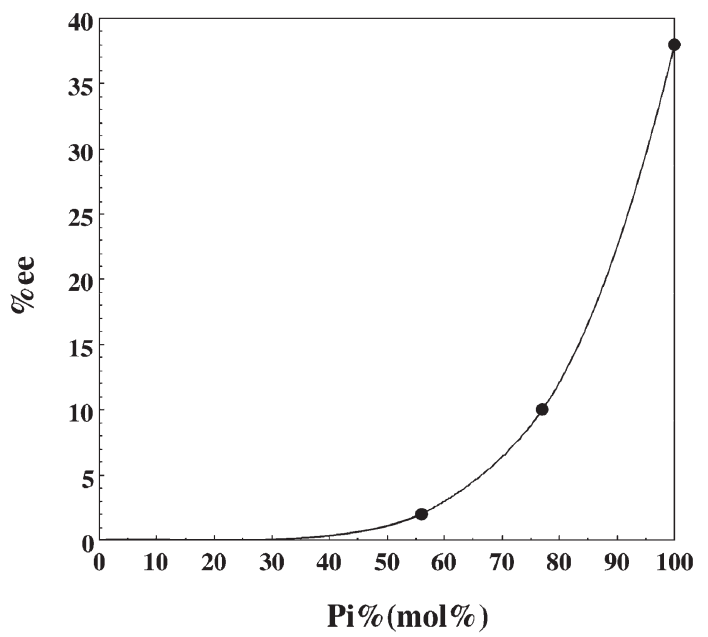

Figure 4. A plot of \%ee in the permeate $v s$. the content of the chiral pinanyl groups (Pi\%) in the copolymer of PSP and trimethylsilylpropyne (Reprinted with permission from ref 76. Copyright 1996, American Chemical Society, Washington, DC.).

polymers had self-membrane-forming abilities. Similarly to the results of poly(disubstituted acetylene)s in 3.7.3, as the content of the chiral groups increased, the enantioselectivities increased as shown in Figure 6. Also, when a small amount of an achiral comonomer was introduced, the enantioselectivity decreased dramatically (Figure 7). Therefore, high content and homogeneity of chiral groups were found to be important for good enantioselectivity again.

Here, we compared between the enantioselectivities of membranes from three poly(phenylacetylene)s having different substituents on the main-chain in Figure 8. It was also observed that the polymers hav- 


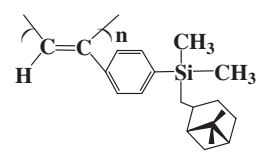

1, Poly(p-PSPA) (46.3)

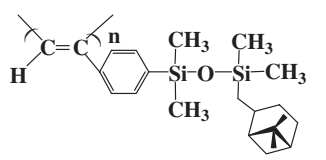

3, Poly(3-PDSPA) (37.0)

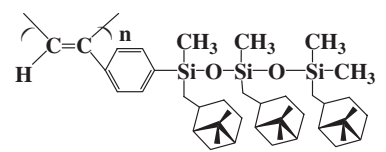

5, Poly(1,3,5-TPTSPA)(59.7)

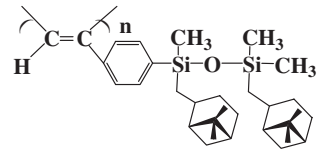

2, Poly(1,3-BPDSPA) (55.7)

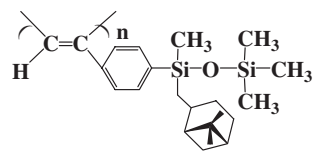

4, Poly(1-PDSPA) (37.0)

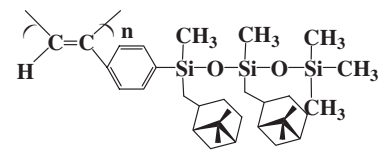

6, Poly(1,3-BPTSPA)(48.4)
Figure 5. Poly(phenylacetylenes) having oligopinanylsiloxanes as side chains used for enantioselectively permeable membranes. The values in the parentheses are the content (wt \%) of the chiral group in the polymer (= membrane).

ing the higher content of the chiral groups showed higher enantioselectivity.

We discovered that a phenylacetylene having a bulky chiral group near polymerizable group polymerized to yield a one-handed helical polymer in $1993 .{ }^{85}$ Similarly, in poly(phenylacetylene)s having oligopinanylsiloxanes as side groups in Figure 3, most of the polymers having a chiral pinanyl group at $\alpha$-position of the oligosiloxane side chains had a main chain chirality, i.e., one-handed helicity. ${ }^{82}$ However, since they had two kinds of chiralities, the effects of the one-handed helical main-chain itself on the enantioselectivity could not be estimated. To estimate the ef-

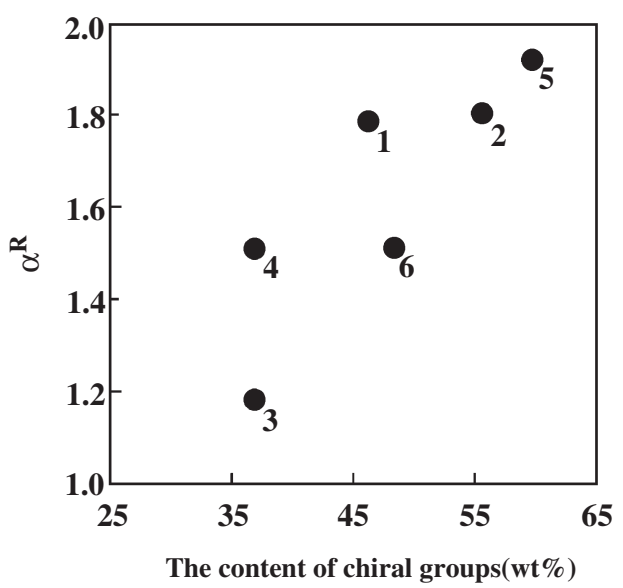

Figure 6. The relationship between $\alpha^{\mathrm{R}}\left(=\mathrm{P}_{\mathrm{R}} / \mathrm{P}_{\mathrm{S}}\right)$ and the content of chiral groups (wt $\%$ ) on permeation of valine aq. through membranes from poly(phenylacetylenes) having oligopinanylsiloxanes as side chains. The numbers corresopond to those in Figure 5.

fect, we synthesized two isomeric polymers (poly(3PDSPA) and poly(1-PDSPA) in Figure 3) which had the same content of the chiral group and different main-chain chiralities. The enantioselectivity of poly(1-PDSPA) membranes which had main-chain chirality was higher than poly(3-PDSPA) membranes which had no main-chain chirality. Therefore, the effect of the main-chain chirality was suggested. ${ }^{82}$

3.7.5 One-Handed Helical Poly(phenylacetylene)s Having No Chiral Groups as Pendants for Enantioselectively Permeable Membranes-The Effect of the One-Handed Helical Main-Chain on the Enantioselectivity - As described above, the effect of the main-chain chirality on the enantioselective permeability was suggested, but it was indirect. To confirm the effect directly, we synthesized several one-handed helical poly(phenylacetylene)s having no chiral groups as pendants by two new methods we discovered.

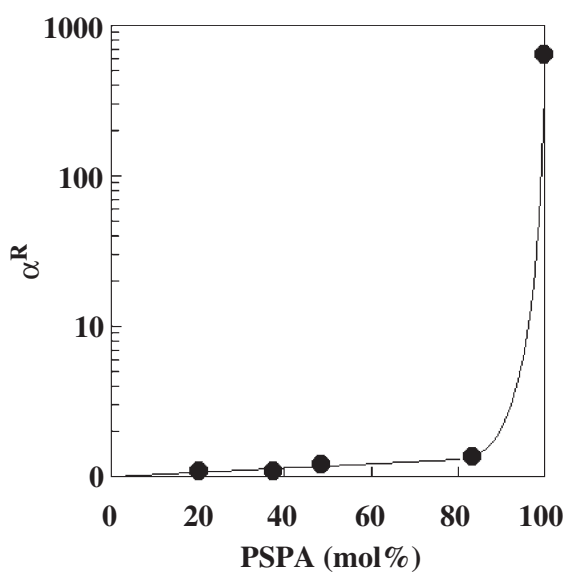

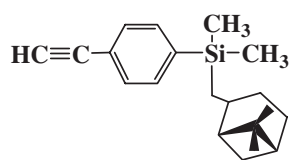

PSPA

chiral monomer<smiles>C#Cc1ccc([Si](C)(C)[Si](C)(C)C)cc1</smiles>
DSPA

achiral monomer

Figure 7. A plot of the copolymer composition (PSPA mol \%) in copoly(PSPA/DSPA) vs. permselectivity $\left(\alpha^{R}=\mathrm{P}_{\mathrm{R}} / \mathrm{P}_{\mathrm{S}}\right)$ of racemic solution of phenylalanine. 


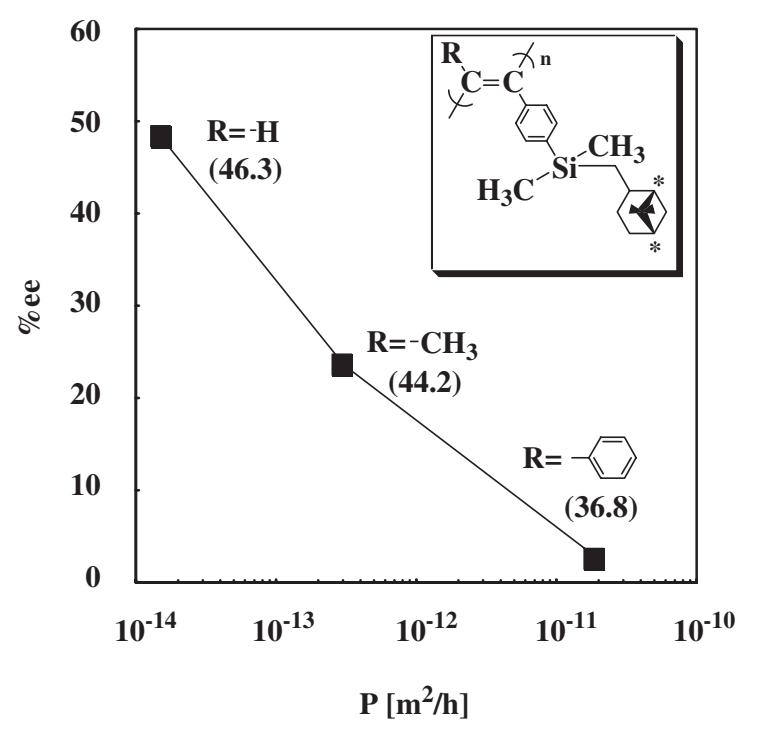

Figure 8. A plot of \%ee in the permeate $v$ s. tryptophan permeability coefficient $(\mathrm{P})$ through membranes from poly(phenylacetylene)s having different substituents at the main chain. The values in the parentheses are the content (wt \%) of the chiral group in the polymer (= membrane).

We synthesized such a new one-handed helical poly(phenylacetylene) by helix-sense-selective polymerization we discovered recently (Figure 9). ${ }^{18,86,87}$ The membrane from the polymer showed enantioselectivities in permeation. The direct evidence of the effectiveness of the main-chain chirality on the enantioselective permeability was obtained. The polymers showing high molar ellipticity had a higher enantioselectivities. ${ }^{88}$

We also synthesized such new one-handed helical poly(diphenylacetylene) membranes ${ }^{89}$ and poly(phenylacetylene) membranes ${ }^{90}$ by in situ elimination of chiral groups from the membranes. The membranes also showed enantioselectivities in permeation (Figures 10 and 11). The direct evidence of the effectiveness of the the main-chain chirality on the enantioselective permeability was obtained again. ${ }^{89,90}$

\subsection{Classification of the Mechanism of Enantioselec- tively Permeable Membranes}

We classified enantioselectively permeable membranes from the view point of structures and preparation methods in 3.3 and described examples of the 4 categories in 3.4-3.7. Here, we will classify the membranes from the view point of mechanisms of permselectivity.

We can divide them into two categories, i.e., solution-selective membranes and diffusion-selective membranes. Similar classification was reported by van der Ent et al. ${ }^{91}$ Solution-selective membranes contain known host molecules having molecular recognition abilities like chiral crown ethers and enzymes. Most of them were composite membranes and needed supporting membranes. The enantioselectivity was caused by the definite carriers which were described in 3.4. On the other hand, diffusion-selective membranes described in 3.7 have no distinct host molecules having molecular recognition sites and were composed of only chiral polymers having membrane forming ability. Membranes described in 3.5 and 3.6 are classified into their intermediate area.

In the case of solution selective membranes, the most important point is how effectively the known hosts are incorporated to permselective membranes. For example, mobile carriers are desirable. However it is not easy to embed host molecules as mobile carriers in supporting membranes. To make the carriers a)

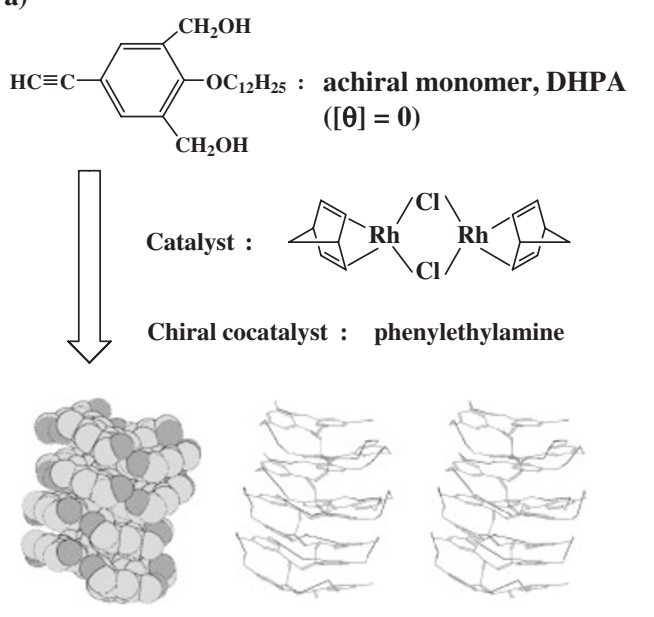

b)

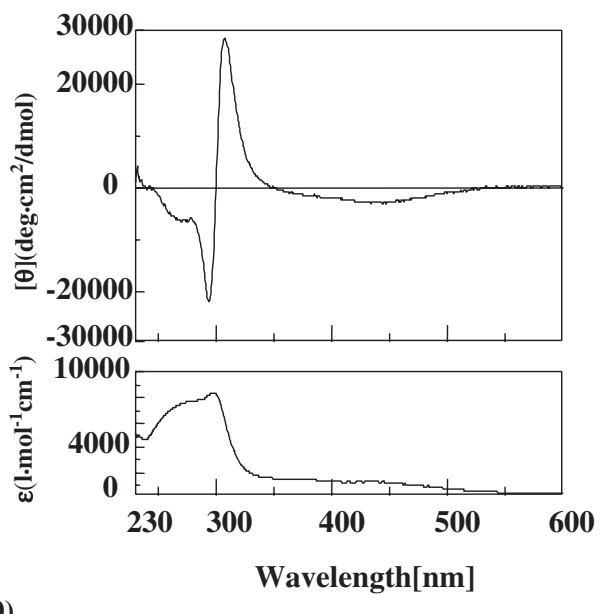

Figure 9. Synthesis of a chiral helical polymer without coexistence of any other chiral moieties by helix-sense-selective polymerization of an achiral phenylacetylene using a chiral catalytic system. a) Chemical structures of the monomer and the catalytic systems, and the stereostructure of the one-handed helical polymer, poly(DHPA). b) CD and UV spectra of poly(DHPA) in $\mathrm{CHCl}_{3}$. 
a)

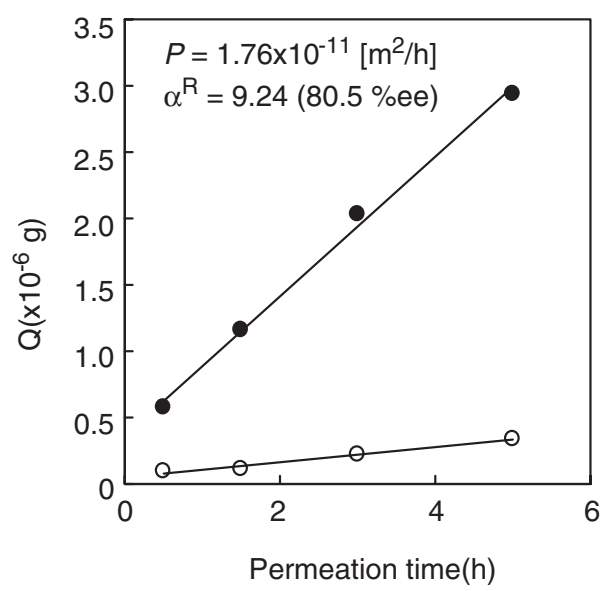

b)

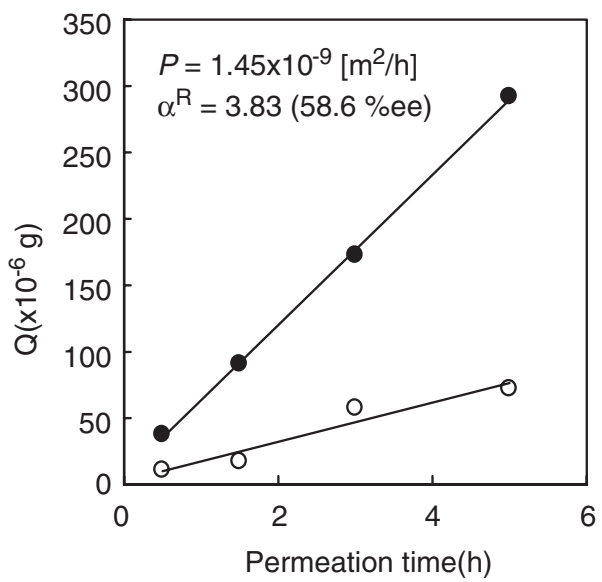

(S) $(\mathrm{R})$

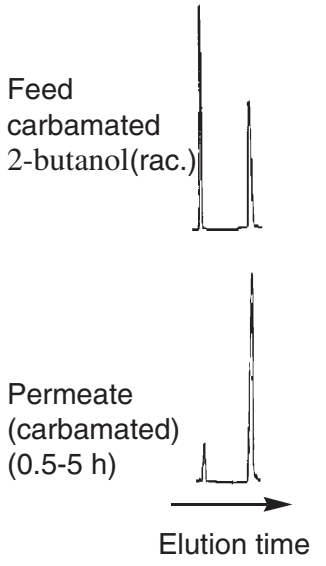

(S) (R)

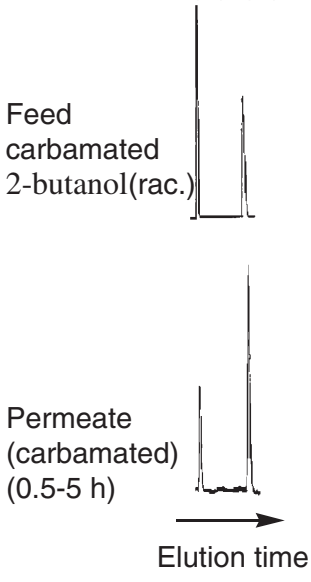

Figure 10. (left) Plots of quantity (Q) of permeated $(\bullet)-(\mathrm{R})-(+)-$ and $(\bigcirc)-(\mathrm{S})-(-)-2-$ butanol vs. permeation time through a) poly(pinanyldimethylsilyldiphenylacetylene) membrane and b) its in-situ depinanylsilylated membrane, respectively. (right) HPLC chromatogram of carbamated 2-butanol. Reprinted with permission from ref 89. Copyright 2003, American Chemical Society, Washington, DC.

mobile, liquid should be used as supporting membranes. Therefore the structures tend to be complicated to maintain the mobility of carriers and to enhance the durability. Although in order to obtain high enantioselectivity, it is very important to minimize nonselective routes in membranes, the composite membranes containing bulky host molecules in liquid have high possibility to make holes and cracks as nonselective routes.

On the other hand, since diffusion-selective membranes do not need supporting membranes such as liquid, and bulky host molecules, they have low possibility to make defects. Therefore, to minimize nonselective permeation routes, diffusion-selective membranes are appropriate. As already described in 3.7, to enhance the content of the chiral groups is effective for increasing permselectivities. However, to obtain high enantioselectivity it was necessary to suppress the permeability. The low permeation rate is a problem to be solved.

\subsection{Improvement of Permeation Rates of Enantiose- lectively Permeable Membranes}

To solve the problem, low permeation rates, we tried to prepare thin membranes. Since our polymers have good membrane forming ability, it was easy to make them thinner. Thin membranes whose thicknesses are about 0.3 and $5.9 \mu \mathrm{m}$ were successfully prepared by casting poly(BSP) on water surface and by preparing asymmetric membranes of poly(PSPA), respectively. Also, we obtain high permeation rates by using pervaporation and evapomeation (Figure 3 ).

\section{CONCLUDING REMARKS}

First, the permselectivity of gas permselective membranes using dendrimers was enhanced owing to their dendrimers features such as inhibition to the segmental mobility, the control of FFV, and a huge number of interior sites with good affinity to permeate molecules. In particular, our polydendrons showed much better oxygen permselectivities than conven- 


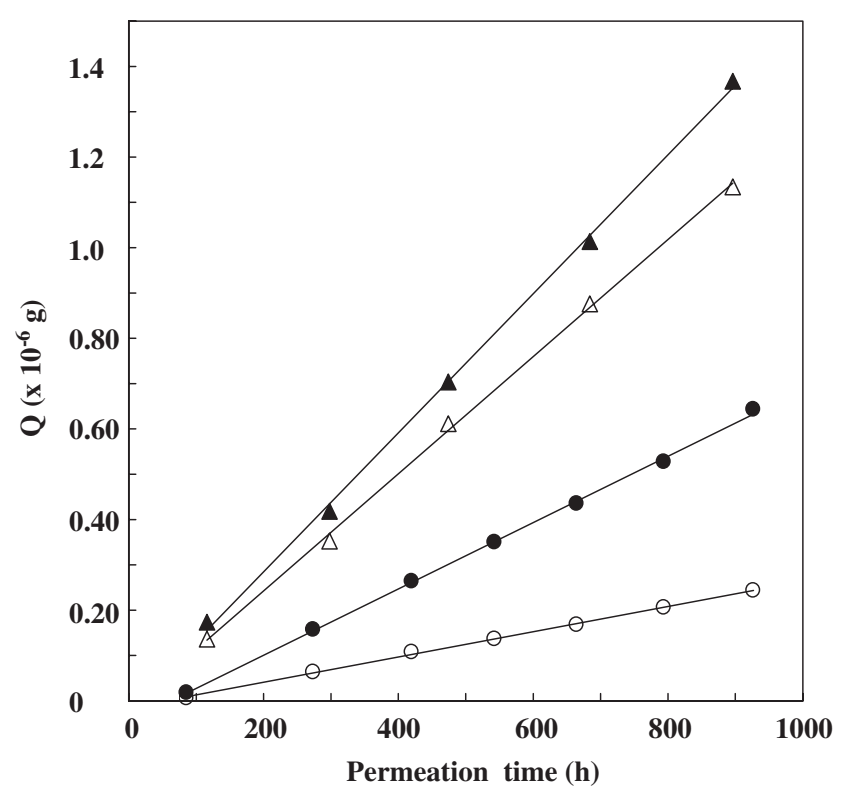

Figure 11. Plots of quantity (Q) of permeated (R)- and (S)phenylalanine (feed: $0.50 \mathrm{wt} \%$ racemic aqueous solution) $v s$. permeation time through poly(pinanyldimethylsiloxyphneylacetylene) $(\bullet, \bigcirc)$ and its in-situ depinanylsilylated membrane $(\boldsymbol{\Delta}$, $\triangle$ ). Solid symbol: (R)-isomer, open symbol: (S)-isomer. Reprinted with permission from ref 90. Copyright 2005, American Chemical Society, Washington, DC.

tional polymeric membranes. Since the performance of the dendrimer-membrane separation often depended on the space among dendrimer molecules, in order to clarify the effect of dendrimer-structure on their permselective behavior, it would be necessary to design new dendrimer-membranes which can vanish or decrease the space among dendrimer molecules, or show the negligible permeation through the space among dendrimer molecules.

Second, the advantages of our macromolecular design of one-handed helical poly(substituted acetylenes) as materials for enantioselectively permeable membranes were shown as follows. 1) high permselectivity was attained by using one-handed helical polymers with high content of the chiral groups. By using this method, it was easy to prepare such membranes. 2) The low permeation rate was improved by using thinner membranes. Since these materials have good self-membrane forming abilities, it was not difficult to prepare such membranes. If pure onehanded helical polymers with maintaining good selfmembrane forming abilities are obtained, enantioselectively permeable membranes having better performance which has both high enantioselectivity and permeation rate at the same time will be realized.

Acknowledgment. Partial financial support through a Grant-in-Aid for Scientific Research (B) (No. 16350061) from Japan Society for the Promotion of Science, through an Asahi Glass Foundation, and through a Grant for Promotion of Niigata University Research Projects is gratefully acknowledged.

\section{REFERENCES}

1. Recent reviews: a) K. Inoue, Prog. Polym. Sci., 25, 453 (2000).

b) D. A. Tomalia and J. M. J. Fréchet, J. Polym. Sci., Polym. Chem. Ed., 40, 2719 (2002).

c) J. M. J. Fréchet, J. Polym. Sci., Polym. Chem. Ed., 41, 3713 (2003).

2. T. Kaneko, T. Horie, M. Asano, T. Aoki, and E. Oikawa, Macromolecules, 30, 3118 (1997).

3. Recent reviews: a) A. D. Schlüter and J. Rabe, Angew. Chem. Int. Ed., 39, 864 (2000).

b) A. Zhang, L. Shu, Z. Bo, and Schl, Macromol. Chem. Phys., 204, 328 (2003).

4. T. Kaneko, T. Horie, M. Asano, S. Matsumoto, K. Yamamoto, T. Aoki, and E. Oikawa, Polym. Adv. Technol., 11, 685 (2000).

5. T. Kaneko, K. Yamamoto, T. Aoki, and E. Oikawa, Polym. Prepr., Jpn., 49, 1876 (2000).

6. T. Kaneko, M. Asano, K. Yamamoto, and T. Aoki, Polym. J., 33, 879 (2001).

7. T. Kaneko, K. Yamamoto, M. Asano, M. Teraguchi, and T. Aoki, J. Membr. Sci., submitted for publication (2005).

8. T. Kaneko, Reports of Mukai Science Technology Foundation, 6, in press (2005).

9. a) T. Kaneko, N. Tsukagoshi, T. Aoki, and E. Oikawa, Annual Meeting of CSJ Preprints, 78, 669 (2000).

b) T. Kaneko, N. Tsukagoshi, K. Takayama, M. Teraguchi, and T. Aoki, Polym. J., 37, under preparation (2005).

10. T. Kaneko, K. Takayama, K. Yamamoto, M. Teraguchi, and T. Aoki, Polym. Prepr., Jpn., 50, 3134 (2001).

11. T. Kaneko, K. Takayama, M. Teraguchi, and T. Aoki, Polym. Prepr., Jpn., 51, 2634 (2002).

12. a) H. Nishide, N. Yoshioka, T. Kaneko, and E. Tsuchida, Macromolecules, 23, 4487 (1990).

b) N. Yoshioka, H. Nishide, T. Kaneko, H. Yoshiki, and E. Tsuchida, Macromolecules, 25, 3838 (1992).

13. T. Aoki, H. Nakahara, Y. Hayakawa, M. Kokai, and E. Oikawa, J. Polym. Sci., Polym. Chem. Ed., 32, 849 (1994).

14. T. Aoki, H. Nakahara, and E. Oikawa, Polym. Prepr., Jpn., 41, 4036 (1992).

15. H. Nishide, T. Kaneko, R. Gotoh, and E. Tsuchida, Mol. Cryst. Liq. Cryst., 233, 89 (1993).

16. Y. Miura, M. Matsumoto, Y. Ushitani, Y. Teki, T. Takui, and K. Itoh, Macromolecules, 26, 6673 (1993).

17. T. Kaneko, T. Yamamoto, H. Tatsumi, T. Aoki, and E. Oikawa, Polymer, 41, 4437 (2000).

18. Y. Umeda, T. Kaneko, M. Teraguchi, and T. Aoki, Chem. Lett., 34, 854 (2005).

19. Y. Liu, R. Wang, and T.-S. Chung, J. Membr. Sci., 189, 231 (2001).

20. L. Shao, T.-S. Chung, S. H. Goh, and K. P. Pramoda, J. Membr. Sci., 238, 153 (2004).

21. T.-S. Chung, M. L. Chng, K. P. Pramoda, and Y. Xiao, Langmuir, 20, 2966 (2004). 
22. Y. Xiao, T.-S. Chung, and Chng, Langmuir, 20, 8230 (2004).

23. J. Fang, H. Kita, and K. Okamoto, J. Membr. Sci., 182, 245 (2001).

24. Y. Yin, L. Yang, M. Yoshino, J. Fang, K. Tanaka, H. Kita, and K. Okamoto, Polym. J., 36, 294 (2004).

25. T. Suzuki, Y. Yamada, and Y. Tsujita, Polymer, 45, 7167 (2004).

26. K. Inoue, A. Miyahara, and T. Itaya, J. Am. Chem. Soc., 119, 6191 (1997).

27. Y. Liu, M. Zhao, D. E. Bergbreiter, and R. M. Crooks, J. Am. Chem. Soc., 119, 8720 (1997).

28. G. P. Perez, W. G. Yelton, R. W. Cernosek, R. J. Simonson, and R. M. Crooks, Anal. Chem., 75, 3625 (2003).

29. B. J. Cha, Y. S. Kang, and Won, Macromolecules, 34, 6631 (2001).

30. C. A. Fail, S. A. Evenson, L. J. Ward, W. C. E. Schofield, and J. P. S. Badyal, Langmuir, 18, 264 (2002).

31. M. Nagale, B. Y. Kim, and M. L. Bruening, J. Am. Chem. Soc., 122, 11670 (2000).

32. B. Y. Kim and M. L. Bruening, Langmuir, 19, 94 (2003).

33. B. Y. Kim and M. L. Bruening, Langmuir, 20, 6074 (2004).

34. A. S. Kovvali, H. Chen, and K. K. Sirkar, J. Am. Chem. Soc., 122, 7594 (2000).

35. A. S. Kovvali and K. K. Sirkar, Ind. Eng. Chem. Res., 40, 2502 (2001).

36. A. S. Kovvali and K. K. Sirkar, Ind. Eng. Chem. Res., 41, 2287 (2002).

37. W. J. Ward III, W. K. Browall, and R. M. Salemme, J. Membr. Sci., 1, 99 (1976).

38. M. Newcomb, R. C. Helgeson, and D. J. Cram, J. Am. Chem. Soc., 96, 7367 (1974).

39. T. Yamaguchi, T. Shinbo, K. Nishimura, and M. Sugiura, Chem. Lett., 1549 (1985).

40. Y. Kikuchi, J. Hattori, Y. Mori, and T. Kajiyama, Kagakukougaku Ronbunshu, 15, 617 (1989).

41. T. Kakuchi, T. Yokota, and K. Yokota, Polym. J., 22, 199 (1990)

42. J. D. Clark, B. Han, A. S. Bhown, and S. R. Wickramasinghe, Sep. Purif. Technol., 42, 201 (2005).

43. P. J. Pickering and J. B. Chushuri, Chirality, 9, 261 (1997).

44. H. M. Krieg, J. C. Breytenbach, and K. I. Keizer, J. Membr. Sci., 164, 177 (2000).

45. H. M. Krieg, J. Lotter, K. I. Keizer, and J. C. Breytenbach, J. Membr. Sci., 167, 33 (2000).

46. K. Ishihara, N. Suzuki, and K. Matsui, Nippon Kagaku Kaishi, 446 (1987).

47. Y.-D. Long and T.-B. Huang, Gaodeng Xuexiao Huaxue Xuebao, 20, 884 (1999).

48. A. Higuchi, H. Yomogita, B. O. Yoon, T. Kojima, M. Hara, S. Maniwa, and M. Saitoh, J. Membr. Sci., 205, 203 (2002).

49. A. Higuchi, Y. Higuchi, K. Furuta, B. O. Yoon, M. Hara, S. Maniwa, M. Saitoh, and K. Sanui, J. Membr. Sci., 221, 207 (2003).

50. A. Higuchi, A. Hayashi, N. Kanda, K. Sanui, and H. Kitamura, J. Mol. Struct., 739, 145 (2005).

51. A. Higuchi, Y. Ishida, and T. Nakagawa, Desalination, 90, 127 (1993).

52. A. Higuchi, M. Hara, T. Horiuchi, and T. Nakagawa,
J. Memb. Sci., 93, 157 (1994).

53. S. Kiyohara, M. Nakamura, K. Saito, K. Sugita, and T. Sugo, J. Memb. Sci., 152, 143 (1999).

54. S. B. Lee, D. T. Mitchell, L. Trofin, T. K. Nevanen, H. Soderlund, and C. R. Martin, Science, 296, 2198 (2002).

55. L. Giorno, N. Li, and E. Drioli, Biothechnol. Bioeng., 84, 677 (2003).

56. B. B. Lakshmi and C. R. Martin, Nature, 388, 758 (1997).

57. A. Skolaut and J. Retey, Angew. Chem., Int. Ed., 41, 2960 (2002).

58. E. Miyako, T. Maruyama, N. Kamiya, and M. Goto, J. Am. Chem. Soc., 126, 8622 (2004).

59. E. Miyako, T. Maruyama, N. Kamiya, and M. Goto, Chem. Eur. J., 11, 1163 (2005).

60. E. Miyako, T. Maruyama, F. Kubota, N. Kamiya, and M. Goto, Langmuir, 21, 4674 (2005).

61. E. Yashima, J. Noguchi, and Y. Okamoto, Chem. Lett., 1959 (1992).

62. E. Yashima, J. Noguchi, and Y. Okamoto, J. Appl. Polym. Sci., 54, 1087 (1994).

63. T. Satoh, Y. Tanaka, K. Yokota, and T. Kakuchi, React. Funct. Polym., 37, 293 (1998).

64. A. Maruyama, N. Adachi, T. Takatsuki, M. Torii, K. Sanui, and N. Ogata, Macromolecules, 23, 2748 (1990).

65. T. Aoki, S. Tomizawa, and E. Oikawa, J. Membr. Sci., 99, 117 (1995).

66. C. Tholen, M. Debruyn, E. Theunisse, Y. Kondo, I. F. J. Vanlelrcom, P. Grobet, M. Yoshikawa, and P. A. Jacob, J. Membr. Sci., 186, 153 (2001).

67. K. Taki, I. Arita, M. Satoh, and J. Komiyama, J. Polym. Sci., Part B: Polym. Phys., 37, 1035 (1999).

68. T. Masawaki, M. Sasai, and S. Tone, J. Chem. Eng. Jpn., 25, 33 (1992).

69. J.-M. Hong, P. E. Anderson, J. Qian, and C. R. Martin, Chem. Mater., 10, 1029 (1998).

70. A. Dzgoev and K. Haupt, Chirality, 11, 465 (1999).

71. M. Yoshikawa, J. Izumi, T. Kitao, S. Koya, and S. Sakamoto, J. Membr. Sci., 108, 171 (1995).

72. M. Yoshikawa, J. Izumi, T. Kitao, and S. Sakamoto, Macromolecules, 29, 8197 (1996).

73. M. Yoshikawa, T. Ooi, and J. Izumi, J. Appl. Polym. Sci., 72, 493 (1999).

74. L. Donato, A. Figoli, and E. Drioli, J. Pharm. Biomed. Anal., 37, 1003 (2005).

75. T. Aoki, K. Shinohara, and E. Oikawa, Makromol. Chem., Rapid Commun., 13, 565 (1992).

76. T. Aoki, K. Shinohara, T. Kaneko, and E. Oikawa, Macromolecules, 29, 4192 (1996).

77. T. Aoki, K. Shinohara, and E. Oikawa, Polymer, 36, 2403 (1995).

78. T. Aoki, M. Ohshima, K. Shinohara, T. Kaneko, and E. Oikawa, Polym. Commun., 38, 23 (1997).

79. T. Aoki, Y. Kobayashi, T. Kaneko, E. Oikawa, Y. Yamamura, Y. Fujita, M. Teraguchi, R. Nomura, and T. Masuda, Macromolecules, 32, 79 (1999).

80. H. Deguchi, Y. Kobayashi, T. Kaneko, and T. Aoki, Polym. Prepr., Jpn., 49, 3550 (2000).

81. Y. Kobayashi, T. Aoki, T. Kaneko, and E. Oikawa, Polym. Prepr., Jpn., 48, 2457 (1999). 
82. T. Aoki, T. Fukuda, K. Shinohara, T. Kaneko, M. Teraguchi, and M. Yagi, J. Polym. Sci., A, 42, 4502 (2004).

83. M. Takeuchi, T. Fukuda, T. Kaneko, and T. Aoki, Polym. Prepr., Jpn., 49, 3552 (2000).

84. K. Shinohara, T. Aoki, and T. Kaneko, J. Polym. Sci., A, 40, 1689 (2002).

85. T. Aoki, M. Kokai, K. Shinohara, and E. Oikawa, Chem. Lett., 2009 (1993).

86. T. Aoki, T. Kaneko, N. Maruyama, A. Sumi, M. Takahashi, T. Sato, and M. Teraguchi, J. Am. Chem. Soc., 125, 6346 (2003).
87. T. Sato, T. Aoki, M. Teraguchi, T. Kaneko, and S.-Y. Kim, Polymer, 45, 8109 (2004).

88. D. Tanioka, M. Takahashi, M. Teraguchi, T. Kaneko, and T. Aoki, Polym. Prepr., Jpn., 50, 3093 (2001).

89. M. Teraguchi, J. Suzuki, T. Kaneko, T. Aoki, and T. Masuda, Macromolecules, 36, 9694 (2003).

90. M. Teraguchi, K. Mottate, S.-Y. Kim, T. Aoki, T. Kaneko, S. Hadano, and T. Masuda, Macromolecules, 38, 6367 (2005).

91. E. M. van der Ent, K. van't Riet, J. F. T. Keurentjes, and A. van der Padt, J. Membr. Sci., 185, 207 (2001).

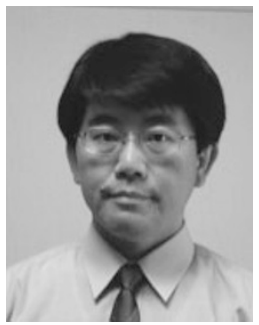

Toshiki Aoki was born in Nagoya, Japan in 1958. He received his Bachelor, Master, and Doctorate Degree (1987) on synthesis and oxygen permeability of graft copolymers from oligosiloxane macromonomers in Department of Applied Chemistry at Nagoya University, Japan. He joined Fluorine Chemistry Division at Government Industrial Research Institute, Nagoya in 1987-1989. He moved to Department of Applied Chemistry at Niigata University in 1989. His carrier at Niigata University has included being Assistant Professor (1989), Associate Professor (1995), and Full Professor (2000). He received the Award for Encouragement of Research in Polymer Science, the Society of Polymer Science, Japan (1990). He worked as a visiting scientist at University of Southern California in 19981999. He also belongs to center for transdisciplinary research at Niigata University in 2003-. His research interest covers synthesis of functional polymers, including synthesis of new chiral polymers for permselective membranes.

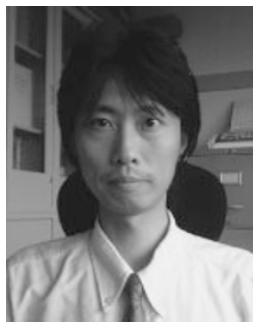

Takashi Kaneko was born in Tokyo, Japan in 1967. He received his B.S. (1990), M.S. (1992) and Ph.D. (1995) degrees in polymer chemistry from Waseda University in Tokyo, Japan, where he received a Research Fellowship for Young Scientists of the Japan Society for the Promotion of Science (1992-1995). He joined the faculty of Niigata University (Japan) in 1995 and was promoted to Full Professor in 2005. He belongs to center for transdisciplinary research at Niigata University in 2003-. He received the Award for Encouragement of Research in Polymer Science, the Society of Polymer Science, Japan (2000). His research interest covers synthesis of macromolecular architectures, magnetic properties of $\pi$-conjugated organic polyradicals, and design and synthesis of chiral polyradicals. 